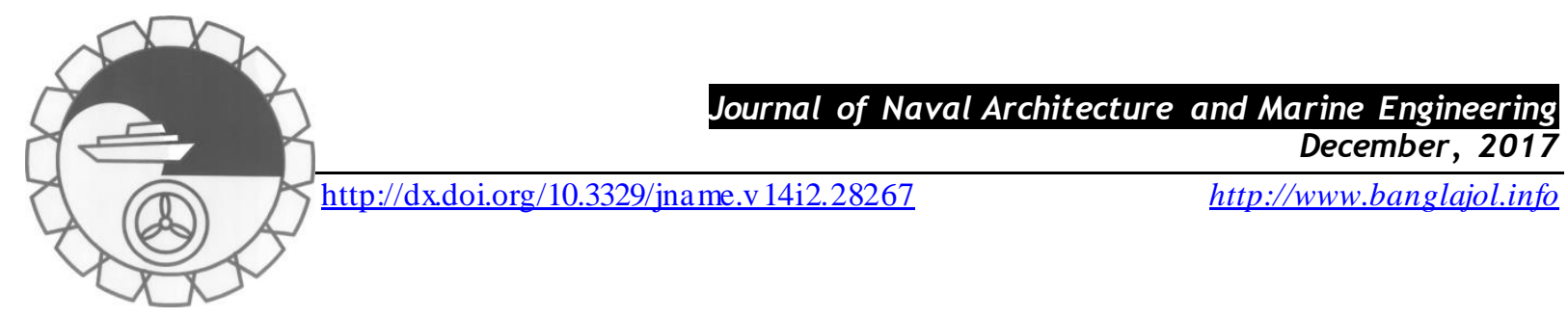

\title{
WAVE INTERACTION WITH FLOATING PLATFORM OF DIFFERENT SHAPES AND SUPPORTS USING BEM APPROACH
}

\author{
A. I. Shirkol ${ }^{1}$, T. Nasar ${ }^{2}$ \\ ${ }^{1}$ Department of Applied Mechanics and Hydraulics, National Institute of Technology Karnataka, Surathkal, Mangalore - \\ 575025, India, anoopshirkol@gmail.com \\ ${ }^{2}$ Department of Applied Mechanics and Hydraulics, National Institute of Technology Karnataka, Surathkal, Mangalore - \\ 575025, India, t.nasar@gmail.com
}

\begin{abstract}
:
Wave interaction with a floating thin elastic plate which can be used as floating platform is analyzed using Boundary Element Method (BEM) for different shapes such as rectangular, circular and triangular. Different support conditions are considered and the performance of the floating platform under the action of ocean waves is explored. The study is performed under the assumption of linearized water wave theory and the floating elastic plate is modelled based on the Euler-Bernoulli beam theory. Using Galerkin's approach, a numerical model has been developed and the hydrodynamic loading on the floating elastic plate of shallow draft (thickness) is investigated. The wave forces are generated by the numerical model for the analysis of the floating plate. The resulting bending moment and optimal deflection due to encountering wave force is analysed. The present study will be helpful in design and analysis of the large floating platform in ocean waves.
\end{abstract}

Keywords: Wave force, boundary element method, floating platform, shapes, support conditions, EulerBernoulli beam, Galerkin's approach.

\begin{tabular}{llll}
\multicolumn{2}{l}{ NOMENCLATURE } & \multicolumn{2}{l}{ Greek symbols } \\
$L$ & Length & $\omega$ & Frequency \\
$h$ & Height & $\rho$ & density \\
$d$ & draft (thickness of plate) & $v$ & Poisson's ratio \\
$E$ & young's modulus & $\phi$ & velocity potential \\
$k$ & wave number & $w$ & Deflection \\
$p$ & pressure & & \\
$G$ & Green's identity & &
\end{tabular}

\section{Introduction}

Paper In late 1960's, numerical techniques such as Boundary Element Method (BEM) and Boundary Integral Equation (BIE) were evolved to solve problems in mechanics. Initially, 2-D potential problem was formulated using direct BIE and this work is extended to solve elastostatic problem by Rizzo (1967). The advantage of BEM as compared to the other numerical methods is ease of reduction of dimensions of the problems i.e from 3$\mathrm{D}$ to 2-D and 2-D to 1-D. Hence it is much easier to generate mesh as compared with the other domain based methods and modelling of infinite domain problems precisely. A significant study on the hydroelastic analysis of the VLFS is performed by researchers in the past decade. Watanabe et al. (2004) presented detail review on the research being performed on the hydroelastic analysis of VLFS due to wave force, drift force, mooring system, profile of seabed and shapes. In the analysis of VLFS, the effect of transverse shear deformation has been neglected due to classical thin plate theory assumptions. The shapes of VLFS have been investigated by Zilman and Miloh (2002), Peter et al. (2004) and Watanabe et al. (2006). In particular studies are mainly carried out for the circular floating elastic plate of shallow draft in finite depth water. Andrianov and Hermans (2005) studied the circular floating structure in finite and infinite water depths. Further, Andrianov and Hermans (2008) considered pontoon type of VLFS and studied the influence of water depth on the structure. The effect of 1813-8235 (Print), 2070-8998 (Online) @ 2017 ANAME Publication. All rights reserved. Received on: June, 2016 
articulation of the floating elastic plate is analyzed by Karmakar and Sahoo (2005) for different water depth.Studies suggested that with increase in stiffness of the articulated spring floating elastic plate behaves as continuous plate. Karmakar et al. (2009) extended the study for multiple articulated floating elastic plates. Riyansyah et al. (2010) presented an innovative approach for reducing hydroelastic response of floating structure by introducing semi-rigid connections into the floating structure system instead of rig id connections.

Meylan and Squire (1996) analyzed the behavior of a flexible ice-floe brought into motion by the action of longcrested sea waves using the eigenfunction expansion method. The study discusses the displacement and 3-D scattering patterns in the water surrounding the ice-floe. Tkacheva (2001a and b) studied the diffraction of the surface waves by the semi-infinite floating plate in water of finite depth using the Wiener-Hopf technique. A closed form solution for the wave reflection and trans mission coefficient and their asymptotic expressions are obtained. In addition to the displacement, strain and pressure distributions over the plate are investigated. Gurert (2002) performed the studies on the interaction of free surface waves with elastic and air cushion platform. Goldshtein and Marchenko (1989) presented the diffraction of plane surface gravitational waves at the edges of an ice cover lying on the surface of an incompressible fluid of infinite depth. The study showed that with the increase in incident wavelength the reflection coefficient tends to zero and the transmission coefficient tends to unity. Ohkusu and Namba (2004) developed an analytical method to analyse the bending vibration of a Very Large Floating Structure of thin and elongated rectangular plate configuration which is floating on water of shallow depth. Using the approach the plate vibration is obtained in an explicit form. Further, An experimental model of transmission of ocean waves by an ice floe is studied by Bennetts et al (2015) by using thin plastic plates with different material properties and thicknesses to model the floe. The diffraction and radiation problem of multiple two-dimensional rectangular bodies floating on a layer of water of finite depth was studied by Zheng and Zhang (2016). Ship collisions with floating ice in which the ship sustains damage are in the shared -energy regime - both the ice and the ship dissipate energy through inelastic deformations was analysed by Kim et al. (2017).

Studies on VLFS have been performed by various authors using coupled equation for deflection of the plate and pressure below the plate surface. Taylor and Ohkusu (2002) obtained closed form expressions for the Green's function for a uniform beam subjected to flexural vibrations. Further, an alternative forms for the free-free beam, in terms of the sinusoidal eigenmodes is developed. The numerical model based on a Galerkin approach, and various components of hydrodynamic loading on a shallow draft beam is investigated by Taylor (2007). The approach is then extended to the case of thin plate (thickness to width ratio of a plate structure is less than 0.1) in waves, where the hydrodynamic effects are fully three dimensional. The alternative procedure of separating problem into diffraction and radiation components used universally for seakeeping analysis is extended for hydroelastic application by Bishop and Price (1979).Further, Gao et al (2011) studied the hydroelastic response of pontoon-type VLFS with a flexible line connection. Mindlin plate theory has been adopted to model the plate and inorder to decouple the fluid-structure interaction problem, the modal expansion method is adopted. Hybrid method is adopted (BEM and FEM) to solve the governing equation and deflection. The study examines the effects of the location and the rotational stiffness of flexible line connection. The study suggested that the hinge and semi-rigid line connections are found to be effective in reducing hydroelastic response of the VLFS, depending on the wavelength. Analytically the solution was given by Liu et al (2012) for wave scattering by submerged horizontal porous plate break water with finite thickness in the context of linear potential theory. The velocity potential has been split into a symmetric and an antisymmetric part. Using eigenfunction expansion matching method all the artificial potentials are determined. To confirm the analytical solution, a multi domain boundary element method solution was developed and the study showed the excellent agree ment between the results obtained by analytical and boundary element method. the meshless numerical method is deloped by Mirafzali et al (2015) to solve such a problem. The fundamental solution method is applied to approximate the velocity potential in the fluid domain. When the water wave encounters the plate, the wave function would not be enough smooth in the edge of plate compared to the other points. Hence, use of Meshless method is an important aspect.Futher, Oblique surface gravity wave scattering by a floating flexible porous plate is investigated in water of finite and infinite depths under the assumption of small amplitude water wave theory and structural response were captured by Koley et al (2017). By employing direct strong coupling method, Kim et al (2013) formulated a complete formulation for 3-D hydrodynamic analysis of floating structures subjected to surface regular waves, as well as other excitation forces. The interaction of oblique monochromatic incident waves with submerged horizontal porous plate was carried out by Cho and Kim (2013), it has been investigated by considering the 2-D linear potential theory. To obtain the analytical solution the eigenfunction expansion method has been applied and the results were compared with the series of experiments conducted in a twodimensional wave tank. They concluded that by selecting optimal design parameters, such as porosity, 
submergence depth, and plate width the performance of the proposed submerged horizontal porous breakwaters can be significantly enhanced. The new solution method based on reducing the problem to finite domain, which contains both the region of variable water depth and the floating thin plate was studied by Wang and Meylan (2002).

Further, Kim et al (2014) proposed a Hydroelastic Design Contour (HDC) which can be used for the preliminary design of pontoon type VLFS. It is easy to predict the maximum bending moment of VLFS in irregular waves by using HDC. To develop the design contour, hydroelastic analyses considering various structural and wave conditions, namely, the bending stiffness and aspect ratio of VLFSs, incident wave length and angle, as well as the sea state has been extensively carried out and Hydroelastic Response Contours (HRCs) have been constructed. The transient response of a pontoon type VLFS subjected to moving load due to airplane landing / take-off was studied by Senjanović et al (2015). Here an approximate solution of free plate natural vibrations, based on a new set of mathematical modes consisting of ordinary products of beam modes and their combinations as additional (extraordinary) modes, for which the natural frequencies are analytically determined using the Rayleigh's quotient, was proposed. The system of modal hydroelastic equations, governing the floating airport forced vibrations, is derived using the Lagrange Equation of the second kind and a simplified s olution procedure is outlined. The study with and without barriers is studied by Nelli et al. (2016). The wave fields reflected and transmitted by plates without barriers are shown to become irregular, as the incident waves become steeper, particularly for the denser plastic and the moored plate. Futher, time-domain incremental nonlinear solution procedure for the hydro-elastoplastic analysis of floating plate structures subjected to external loads was analysed by Yoon and Less (2017), in which elastoplastic material behavior has been considered. Nonlinear hydrostatic analysis of flexible floating structure subjected to self-weight, buoyancy and other external loads where solved using an updated Lagrangian Finite Element formulation which was carried out by Lee and Lee (2016). By considering the reference configuration the nonlinear equation has been linearized and then by using Newton-Raphson method the Finite Element formulation has been solved iteratively. A special numerical integration technique is developed to handle the wet-surface change without re-meshing. To demonstrate the capability of the model, various nonlinear hydrostatic problems were solved. In particular, the results obtained by the model were compared by conducting hydrostatic experimental test. An eigenfunctionmatching method was developed by Meylan et al. (2016) to solve problem of linear water-wave scattering by a circular floating porous elastic plate, and a coupled hybrid BEM-FEM was for the problem in which the plate is of arbitrary shape. Further, Cheng et al (2016) developed analytical, numerical and experimental methods for the hydroelastic analysis of pontoon type VLFS edged with dual horizontal / inclined perforated plates. In analytical method to evaluate diffraction and radiation potentials, Eigen function Expansion-Matching Method (EEMM) for multiple domains has adopted and by using Rayleigh-Ritz method the equation of motion has been solved. The hybrid BEM-FEM solution has been adopted to solve the general cases including inclined perforated anti-motion plates numerically. The series of experiments were also conducted to validate both analytical and numerical model.

The present work is concerned with the hydroelastic response of the floating beams and floating plates. The horizontal dimension in one direction is very large in longish VLFS, such problem can be modelled as floating beam. If the dimension is also large in second direction then the problem can be modelled as a plate. For 2-D problem, a frequency domain based numerical solution is developed. The fluid is modelled as ideal fluid and Euler- Bernoulli theory has been used for the modelling of floating beams or floating plates. The assumptions which are made are: the fluid is assumed to be in viscid and incompressible and the flow is assumed irrotational so that fluid velocity can be described by velocity potential which must satisfy the Laplace equation. The Boundary Element Method (BEM) with free space Green's function is used to solve the governing equations of fluid motion and the displacement of the beam. The present paper investigates the application of boundary element method to compute wave forces, deflection and moment on a floating offshore structure with different support condition such as free-free, simply supported, moored and different shapes such as Rectangular, Circular and Triangular. The floating beam is allowed to move freely in the vertical direction and is always in contact with the fluid. The elastic response of the floating beam is analysed based on the Boundary Element Method (BEM) subjected to regular wave actions. 


\section{Methodology}

The formulation of wave interaction with floating thin elastic plate is based on linearized water wave theory. The floating beam of length $L$ which covers a part of undistributed water surface which is designated as $\mathrm{P}(0 \leq x$ $\leq L$ ) shown in the Fig. 1 (region 2) and is subjected to sinusoidal waves with wavelength $\lambda$.Cartesian coordinate system has been adopted and $x-y$ plane is considered horizontal and z-axis is vertically upward. The incident wave travels from $x=+\infty$ to $x=-\infty$.

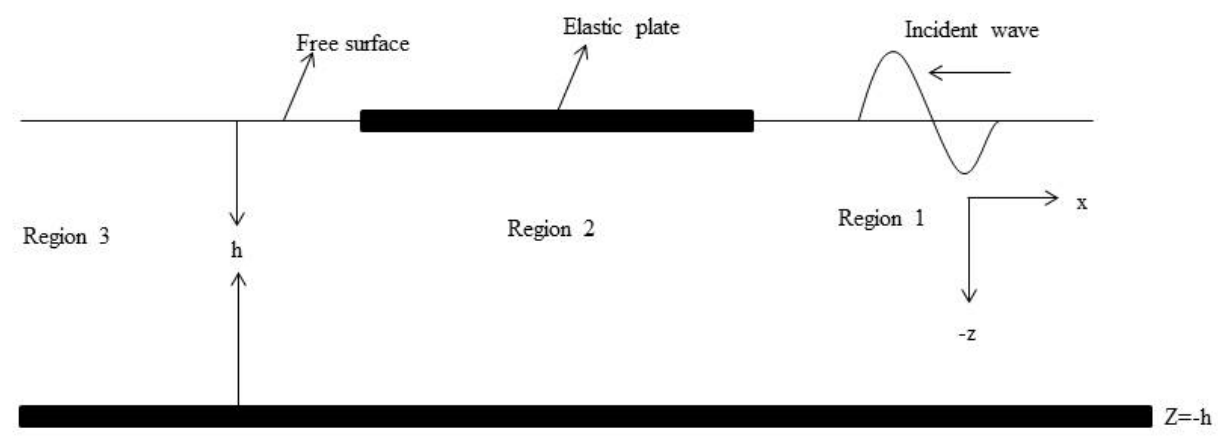

Fig.1: Schematic diagram for floating thin plate

The wavelength $(\lambda)$ of incident wave is assumed to be small as compared with length of plate $L$. Thickness $d$ is assumed to be very small (shallow draft) as compared with other two dimensions of the plate. Fluid particle motion is described by velocity potential based on the assumption of fluid is inviscid, incompressible and irrotational which satisfies the Laplace equation as given below,

$\frac{\partial^{2} \phi}{\partial x^{2}}+\frac{\partial^{2} \phi}{\partial z^{2}}=0$ for $-\infty<x<\infty,-h<z<0$.

The elastic plate is considered to be satisfying Euler Bernoulli equation and the plate deflection $w$ is given by,

$\left(E I / \rho g L^{4}\right)^{4} \cdot \frac{d^{4} w}{d x^{4}}-\mu k w=p$, for $-0 \leq x \leq L, z=0$,

where, $E I=E d^{3} / 12\left(1-v^{2}\right)$ is the flexural rigidity of the plate, $E$ is the Young's Modulus, $d$ is plate thickness or draft, $v$ is Poisson's ratio, $\mu=h / L$ and $h$ is water depth. In order to model the floating elastic plate Euler Bernoulli beam theory has been adopted. The relationship between displacement $w$ and velocity potential $\phi$ is given by,

$$
\frac{p}{\rho}=-i \omega \phi-g w, \text { on } z=0
$$

where, $p$ is pressure, $\omega$ is frequency and $\rho$ is density of water. The draft is assumed to be small, pressure below of the plate is taken at $Z=0$ which is expressed as an integral equation using the Green's function $G\left(x_{0}, x\right)$ as

$$
p(x)+K \int_{0}^{L} G\left(x, x_{o}\right) p(x) d x_{0}=e^{i k x}-w(x),
$$

where, $K=k \tanh k \mu$ and $k=2 \pi / \lambda$ is wave number. The hydroelastic behavior of the beam can be obtained based on the Galerkin's formulation to represent deflection $w$ and pressure $p$. The rigid body modes of the beam and finite set of sinusoidal functions is considered which are given by,

$$
w(x)=\sum_{n=0}^{N} w_{n} \varphi_{n}(x), p(x)=\sum_{n=0}^{N} p_{n} \varphi_{n}(x) .
$$

where,

$$
\varphi_{n}(x)=\sin (n-1) \frac{\pi}{2}(1+x), n \geq 2
$$

By combining Equations (2), (4) and (5) and using the weak formulation of Galerkin method as described in $\mathrm{Au}$ and Brebbia (1982) we have.

$$
2 \pi \phi(x)-2 \pi \phi_{I}(x)=\int_{P}\left[\phi(\xi) \frac{\partial G(x, \xi)}{\partial n}-G(x, \xi) \frac{\partial \phi(\xi)}{\partial n}\right] d P,
$$

where, $\phi^{I}$ is the incident wave potential given by: 
$\phi_{I}=\frac{i g a}{\omega} \frac{\cosh k(x+h)}{\cosh k h} e^{i k x}$.

At the free surface, sea bottom and at fluid structure interface boundary conditions are given by

$\frac{\partial \phi}{\partial z}-\frac{\omega^{2}}{g} \phi=0$, on $z=0$

$\frac{\partial \phi}{\partial z}=-i \omega w$, on $\mathrm{p}$

$\frac{\partial \phi}{\partial z}=0$, on $\mathrm{z}=-\mathrm{h}$

where, $g$ is the acceleration due to gravity. The free surface dispersion relation is given by

$g k \tanh k h=\omega^{2}$.

Substituting fluid boundary conditions (8a-8c) in Equation (6) we have,

$2 \pi\left\{\frac{i}{\omega \rho_{w}} p(x)+\frac{i g}{\omega} u_{3}(x)\right\}-2 \pi \phi_{I}(x)=\int_{P} \frac{i \omega}{\rho_{w} g} p(\xi) G(x, \xi) d P$,

where, $u_{3}$ is vertical displacement and $u_{1}$ is horizontal displacement of the plate. The displacement of the plate according to virtual work principle is given by,

$-\int_{V} \omega^{2} \rho_{s} u_{3}(x) \delta u_{3}(x) d V+\int_{V} \sigma(x) \delta \in(x) d V=\int_{P} p(x) \delta u_{3}(x) d P$,

where, $d V$ is the volume domain lying below the plate surface (region 2), $\sigma(x)$ and $\varepsilon(x)$ are the stress and strain of the plate which obey hooks law given by,

$\sigma(x)=E \in_{x}(x)$ and $\in_{x}(x)=-x_{3} \frac{\partial^{2} u_{3}}{\partial x_{1}^{2}}$.

Substituting the relation between stress and strain in Equation. (11), we obtain

$$
\begin{aligned}
& -\int_{V} \omega^{2} \rho_{s} u_{3}\left(x_{1}\right) \delta u_{3}\left(x_{1}\right) d V+\int_{V} E x_{3}{ }^{2} \frac{\partial^{2} u_{3}\left(x_{1}\right)}{\partial x_{1}^{2}} \frac{\partial^{2} \delta u_{3}\left(x_{1}\right)}{\partial x_{1}^{2}} d V=\int_{P} p\left(x_{1}\right) \delta u_{3}\left(x_{1}\right) d P . \\
& \frac{2 i \pi}{\rho_{w} \omega} \int_{P} p\left(x_{1}\right) \delta p\left(x_{1}\right) d P+\frac{2 i \pi g}{\omega} \int_{P} u_{3}\left(x_{1}\right) \delta p\left(x_{1}\right) d P-\int_{P} 2 \pi \phi_{I}\left(x_{1}\right) \delta p\left(x_{1}\right) d P=\frac{i \omega}{\rho_{w} g} \int_{P} p\left(\xi_{1}\right) G\left(x_{1}, \xi\right) \delta p\left(x_{1}\right) d P d P .
\end{aligned}
$$

Equation (14) represents the fluid pressure exerted on the plate due to waves and can be modelled as two noded line element. At each node single degree of freedom is considered. Two noded beam element is considered for thin plate and at each node two degrees of freedom (translation and rotation) is considered. The standard interpolation functions and scheme of interpolation is adopted to solve fluid structure problem

Using interpolation function

$$
\begin{aligned}
& h^{1}=\frac{1}{2}(1-r) o r h^{1}=\frac{1}{2}(1-\xi) \\
& h^{2}=\frac{1}{2}(1+r) o r h^{2}=\frac{1}{2}(1+\xi) \\
& H_{u}=\left[h_{w(1)} h_{\theta(1)} h_{w(2)} h_{\theta(1)}\right] \\
& H^{e}=\left[h^{(1)} h^{(1)}\right]
\end{aligned}
$$

Scheme of interpolation 


$$
\begin{aligned}
& x_{1}=H^{e} x_{1}{ }^{e} ; x_{1}{ }^{e}=\left[x_{1}{ }^{(1)} x_{2}{ }^{(2)}\right]^{T} \\
& \xi_{1}=H^{e} \xi_{1} ; \xi_{1}^{e}=\left[\xi_{1}^{(1)} \xi_{2}{ }^{(2)}\right]^{T} \\
& p=H p=\sum_{e=1}^{N} H^{e} p^{e} ; p^{e}=\left[p^{(1)} p^{(2)}\right]^{T} \\
& u_{3}=H_{u} u_{3}=\sum_{e=1}^{N} H_{u}{ }^{e} u_{3}{ }^{e} ; u_{3}{ }^{e}=\left[w^{(1)} \theta^{(1)} w^{(2)} \theta^{(2)}\right]
\end{aligned}
$$

Substituting the above equations in Equation (13) and (14) and using Galerkin's formulation and combining the boundary conditions of the fluid part, the deflection $w$ and pressure $p$ for the elastic plate can be given as follows,

$\left[\omega^{2} \rho_{s} H \int_{-1}^{1} H_{u}{ }^{T} H_{u} \operatorname{det} J d r-\frac{E I}{B} \int_{-1}^{1}\left(\frac{\partial^{2} H_{u}}{\partial r^{2}}\right)^{T}\left(\frac{\partial^{2} H_{u}}{\partial r^{2}}\right) \operatorname{det} J d r\right] u_{3}+\left[\int_{-1}^{1} H_{u}{ }^{T} H \operatorname{det} J d r\right] p=0$

$\left[\int_{-1}^{1} H^{T} H_{u} \operatorname{det} J d r\right] u_{3}+\left[\frac{1}{\rho_{w} g} \int_{-1}^{1} H^{T} H_{u} \operatorname{det} J d r\right] p-\left[\frac{\omega^{2}}{2 \pi \rho_{w} g^{2}} \int_{-1}^{1} H^{T}(s)\left[\int_{-1}^{1} H(r) G\left(x_{1}, \xi_{1}\right) \operatorname{det} J d r\right] \operatorname{det} J d s\right] p$

$=a \int_{-1}^{1} H^{T} \exp \left(x_{1}\right) \operatorname{det} J d r$

where, $H$ is the structural stiffness, $B$ is the width, $I$ is moment of inertia and det $J=l / 2$ Equation (14), (18) and (19) are solved numerically. The matrix form of Equation (18 and 19) is given below

$\left[\begin{array}{cc}S_{m}-S_{k} & S_{c} \\ F_{c} & F_{m}-F_{G}\end{array}\right]\left[\begin{array}{c}u_{3} \\ p\end{array}\right]=\left[\begin{array}{c}0 \\ F_{I}\end{array}\right]$,

Where,

$S_{m}=\omega^{2} \rho_{s} H \int_{-1}^{1} H_{u}{ }^{T} H_{u} \operatorname{det} J d r$ is structural mass,

$S_{k}=\frac{E I}{B} \int_{-1}^{1}\left(\frac{\partial^{2} H_{u}}{\partial r^{2}}\right)^{T}\left(\frac{\partial^{2} H_{u}}{\partial r^{2}}\right) \operatorname{det} J d r$ is structural stiffness,

$F_{m}=\frac{1}{\rho_{w} g} \int_{-1}^{1} H^{T} H_{u} \operatorname{det} J d r$ is fluid stiffnes s,

$F_{G}=\frac{\omega^{2}}{2 \pi \rho_{w} g^{2}} \int_{-1}^{1} H^{T}(s)\left[\int_{-1}^{1} H(r) G\left(x_{1}, \xi_{1}\right) \operatorname{det} J d r\right] \operatorname{det} J d s$, is fluid mass and

$F_{I}=a \int_{-1}^{1} H^{T} \exp \left(x_{1}\right) \operatorname{det} J d r$ is incident pressure.

By considering the stiffness mass and coupling matrix as explained in Equation (20) the study state response of elastic plate can be obtained. Fluid pressure is divided into three components such as diffraction pressure, hydrostatic pressure, and radiation pressure.

Total pressure, $P=P_{d}+P_{s}+\mathrm{P}_{\mathrm{r}}$

$P_{d}=\left(F_{m}-F_{G}\right)^{-1} F_{I}$

$P_{s}=-\rho_{w} g u_{3}$

$p_{\mathrm{r}}=p-p_{d}-p_{s}$ 
A. I. Shirkol, T. Nasar /Journal of Naval Architecture and Marine Engineering, 14(2017) 11 5-133

The wave pressure can be calculated as explained in Eqn. (22), Vice-versa is also possible i.e with wave forces as known parameters the displacement can be calculated.

\subsection{Free-Free edge condition}

In the case of Free-Free beam, the floating plate is allowed to move freely in the vertical direction with no support at the ends. Due to this type of support condition, the movement in vertical direction is not restrained and they are always in contact with the fluid. The boundary conditions (Force and Kinematic) satisfy the following relations at their ends given by Shirkol et al (2016).

$\frac{d^{2} w}{d x^{2}}=0$ and $\frac{d^{3} w}{d x^{3}}=0$ at $x=0$ and $x=L$

By applying the structure boundary conditions given in Equation (23) we can formulate stiffness and mass matrix of the structure,

$$
\begin{aligned}
S_{k} & =\left[\begin{array}{cccc}
12 E I / L^{3} & 6 E I / L^{2} & -12 E I / L^{3} & 6 E I / L^{2} \\
6 E I / L^{2} & 4 E I / L & -6 E I / L^{2} & 2 E I / L \\
-12 E I / L^{3} & -6 E I / L^{2} & 12 E I / L^{3} & -6 E I / L^{3} \\
6 E I / L^{2} & 2 E I / L & -6 E I / L^{3} & 4 E I / L
\end{array}\right] \\
S_{m} & =\frac{\rho A L}{420}\left[\begin{array}{cccc}
156 & 22 L & 54 & -13 L \\
22 L & 4 L^{2} & 13 L & -3 L^{2} \\
54 & 13 L & 156 & -22 L \\
-13 L & -3 L^{2} & -22 L & 4 L^{2}
\end{array}\right]
\end{aligned}
$$

\subsection{Simply-supported edge condition}

In the case of simply supported beam, the floating plate is allowed to move freely in the vertical direction but at the ends of the beam which is attached with the simple support. At the plate ends deflection and bending moment satisfies the following force boundary condition.

$\frac{d^{2} w}{d x^{2}}=0 y=0$ at $x=0$ and $x=L$

Based on the vertical restrained the stiffness matrix (Equation 24) can be modified.

\subsection{Moored edge condition}

In the case of moored condition, the floating plate is allowed to move freely in the vertical direction but at the ends of the beam which is attached with the simple spring of certain stiffness. Due to this support the deflection in vertical direction is added with stiffness coefficients at the supports and they are always in contact with the fluid. The deflection and bending moment satisfies the relation.

$$
\frac{d^{2} w}{d x^{2}}=0 \text { and } \frac{d^{3} w}{d x^{3}}=K_{m} w \text { at } x=0 \text { and } x=L
$$

where, $K_{m}$ is moored stiffness

\section{Results and Discussion}

Hydroelastic analysis of the floating platform with different edge conditions is carried out for finite water depth condition. The resulting bending moment due to encountering waves and plate deflection are discussed here. In the present study, convergence test for the deflection is performed and it is observed that, convergence takes place for $N \geq 50$. Numerical parameters considered in the computation are given in Table 1 . 
A. I. Shirkol, T. Nasar / Journal of Naval Architecture and Marine Engineering, 14(2017) 11 5-133

Table 1: Details of numerical models used to study the analysis

\begin{tabular}{|l|l|}
\hline Parameters & Magnitude \\
\hline Length, $L$ & $10 \mathrm{~m}$ \\
\hline Breadth, $B$ & $50 \mathrm{~cm}$ \\
\hline Draft, $d$ & $38 \mathrm{~mm}$ \\
\hline Youngs modulus, $E$ & $103 \mathrm{Mpa}$ \\
\hline Structural density, $\rho_{s}$ & $220 \mathrm{~kg} / \mathrm{m}^{5}$ \\
\hline Density of water, $\rho_{w}$ & 1025 \\
\hline Water depth, $h$ & $20 \mathrm{~m}$ \\
\hline Wave periods & 0.5 to $3 \mathrm{~s}$ \\
\hline
\end{tabular}

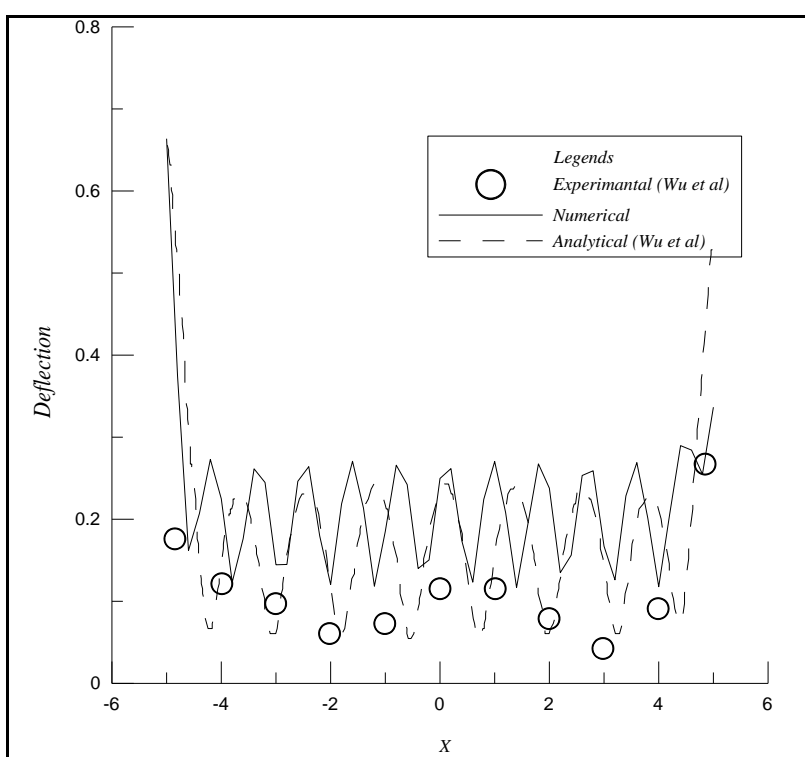

(a)

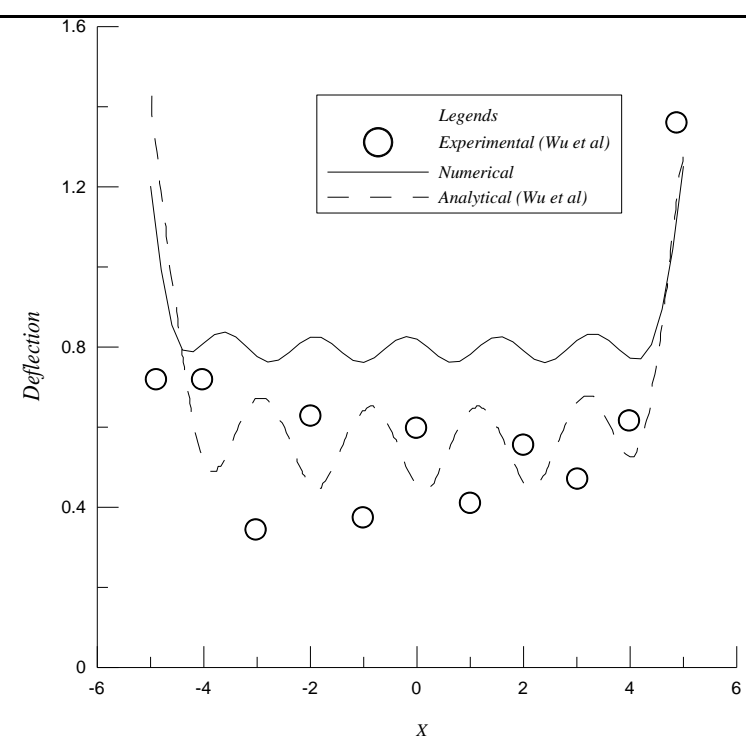

(b)

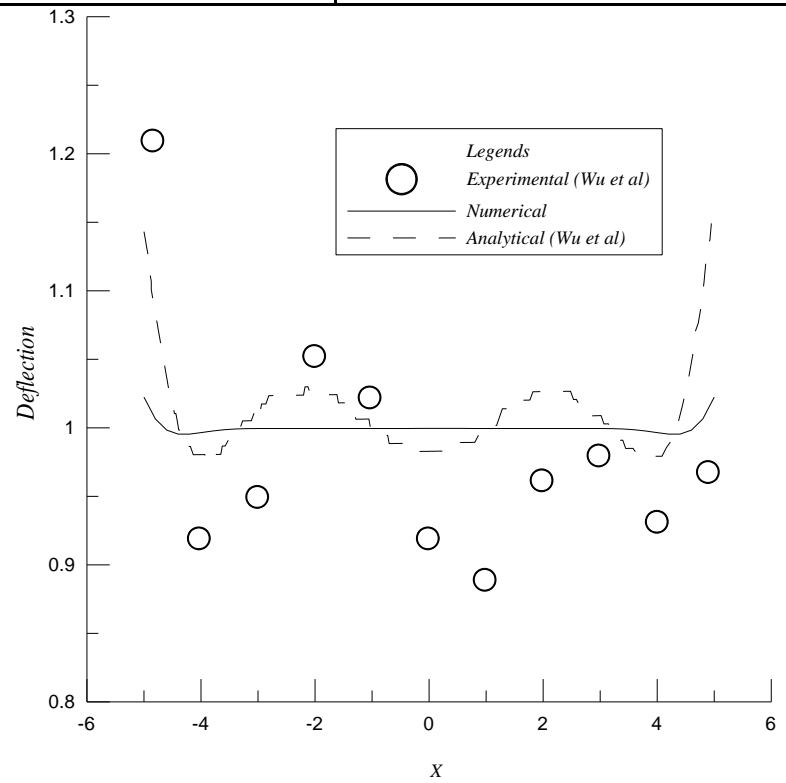

Fig. 2: Amplitude of displacement: (a) $T=0.7 \mathrm{~s}$; (b) $T=1.429 \mathrm{~s}$; (c) $T=2.875 \mathrm{~s}$.

In order to examine the code, the numerical results obtained are compared with the experimental and analytical results obtained by $\mathrm{Wu}$ et al. (1995). The trend in variation of displacement is found to be in agreement with experimental and analytical results for three different wave periods $T=0.7 \mathrm{~s}$ (Fig.2a), $T=1.429 \mathrm{~s}$ (Fig.2b) and $T$ $=2.875 \mathrm{~s}$ (Fig. 2c) and for free-free edge conditions. At the edges, non-dimensional displacements are 0.6637 and 0.3365 , and that of analytical values are 0.656 and 0.528 for the encountering wave period of $T=0.7 \mathrm{~s}$ (Fig. 2a). Further, it is observed that the numerical values at edges are 1.2019 and 1.2516, whereas analytical values 
are 1.430 and 1.280 for $T=1.429 \mathrm{~s}$ (Fig. 2b). It is learnt that the difference is due to the consideration of added mass and hydrodynamic damping in the analytical and experimental work. Both in analytical and in numerical models, the convergence is achieved for $N \geq 50$. Bending moment for Free-Free beam condition is shown in Fig.3 for two different wave periods $T=0.7 \mathrm{~s}$ (Fig.3a) and $T=2.87 \mathrm{~s}$ (Fig. 3b). For validation of the numerical model, it should satisfy the boundary condition as mentioned in Equation (23) i.e at the edges bending moment must become zero.
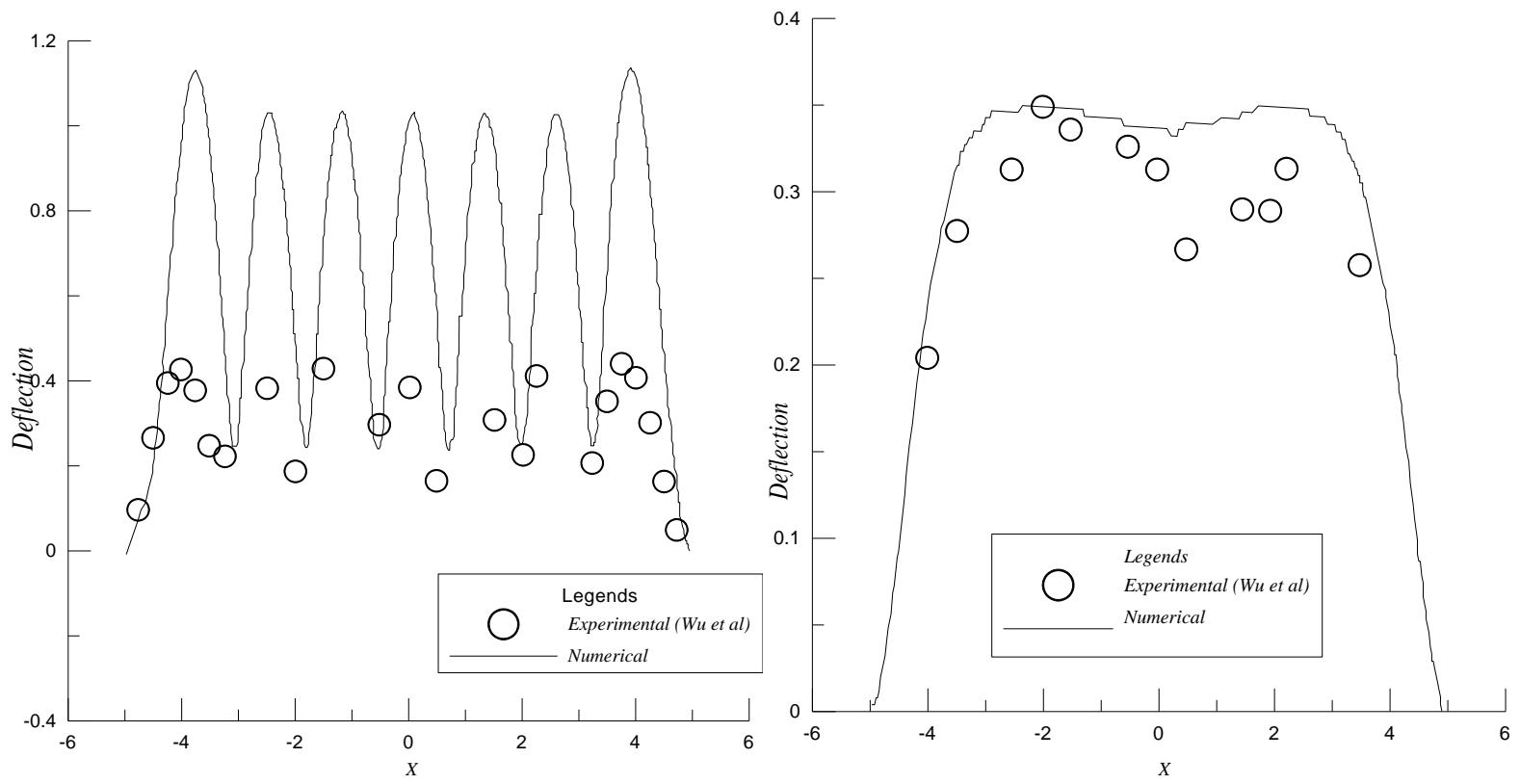

Fig. 3: Amplitude of bending moment: (a) $T=0.7 \mathrm{~s}$; (b) $T=2.87 \mathrm{~s}$.

Fig.3a describes the experimental and numerical values for free-free conditions and at the edges, zero bending moment values are observed from the numerical model, whereas experimental values are 0.987 and 0 . The variation of real and imaginary parts of hydrostatic, diffraction, radiation and total pressure over the plate length is reported in Fig.4. Computation is performed for the parameters explained in Table 1. Comparison of the results shows that the total pressure acting below the plate does not exhibit much oscillation than the individual radiation, diffraction and hydrostatic pressures. The effect of diffraction by the shallow draft beam does not cancels the incident wave but the magnitude of the total diffraction forces increases almost monotonically towards its maximum amplitude.
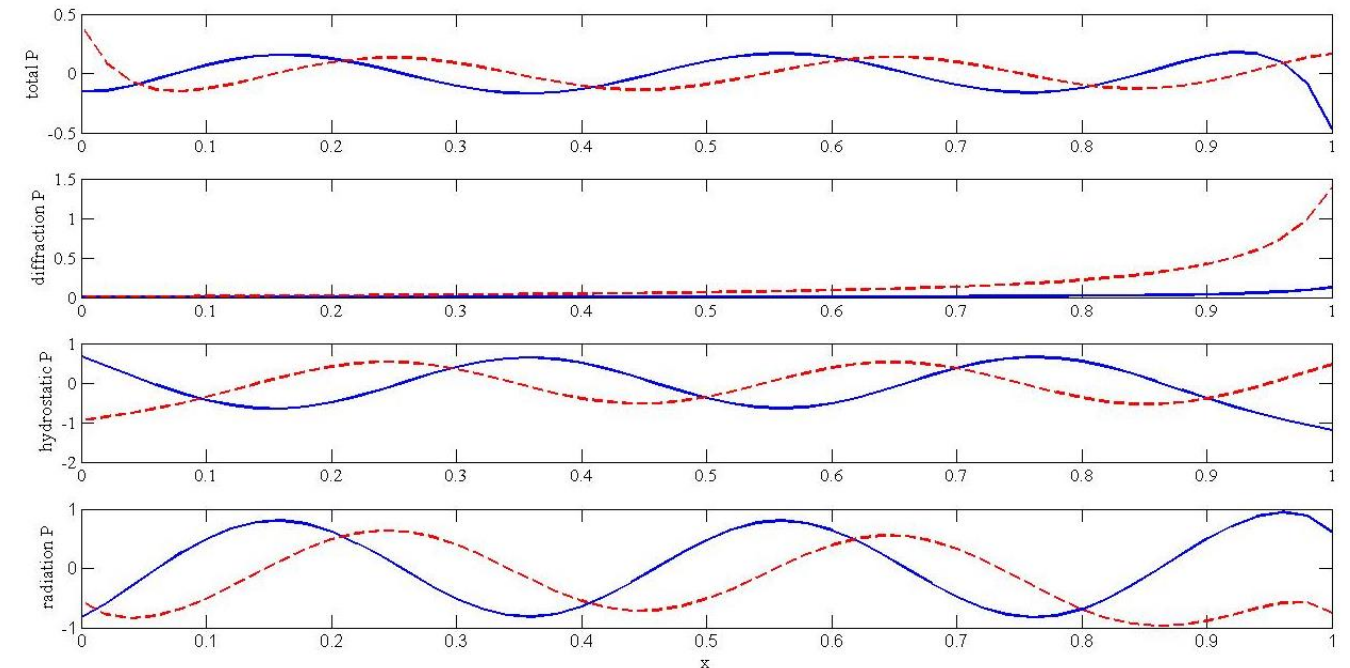

Fig 4: Total, diffraction, hydrostatic and radiation Force on the floating plate ( Absolute, $=-----$ Imaginary)

The analysis is also performed by considering two different edge conditions such as simply-supported and moored support. The study showed that assembling of stiffness matrix in the numerical model plays a major role 
A. I. Shirkol, T. Nasar /Journal of Naval Architecture and Marine Engineering, 14(2017) 11 5-133

in the calculation of deflection and bending moment of the floating structure. In the case of moored edge condition, added spring stiffness $K_{m}=10 \mathrm{~N} / \mathrm{m}$ [Equation (27)] is considered for the numerical computation.

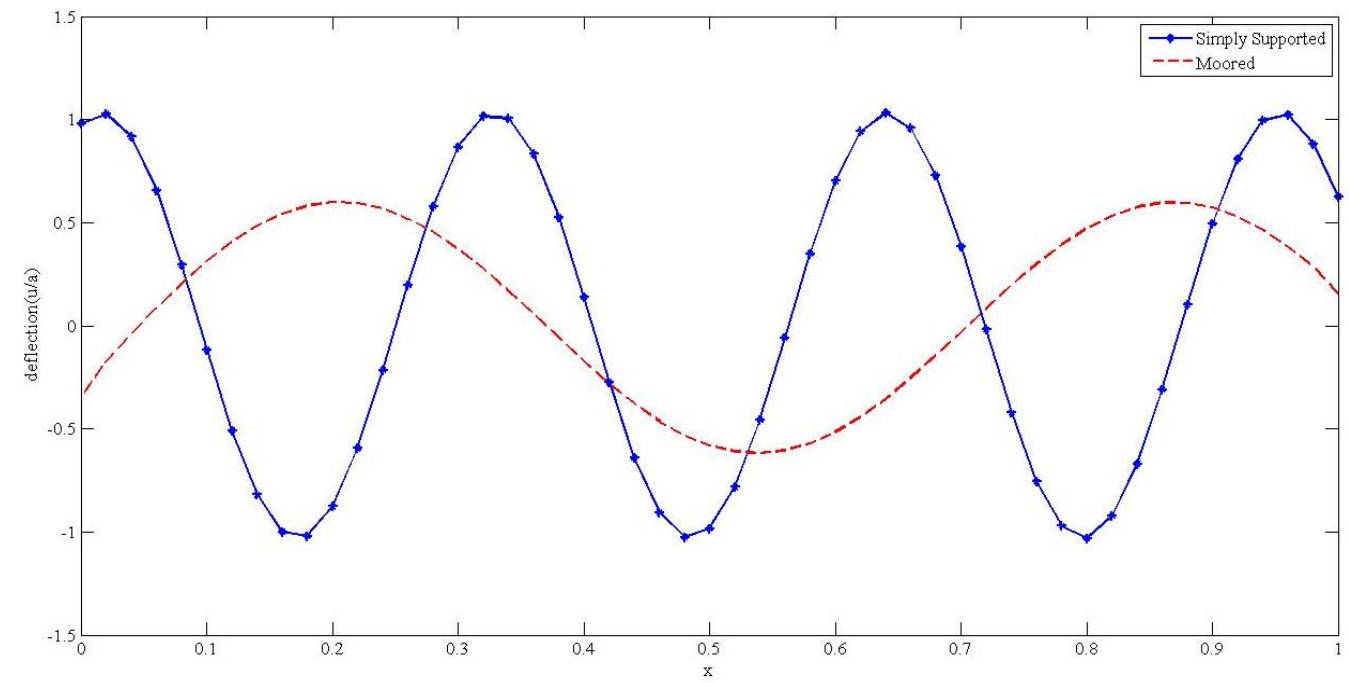

Fig. 5: Comparis on of deflection for rectangular plate with moored and simple support conditions $(L / \lambda=12)$.

Deflection of the floating elastic plate for moored and free-free support conditions is projected in Fig. 5. It is observed that plate deflection is less for moored edge condition as compared to simply-supported.

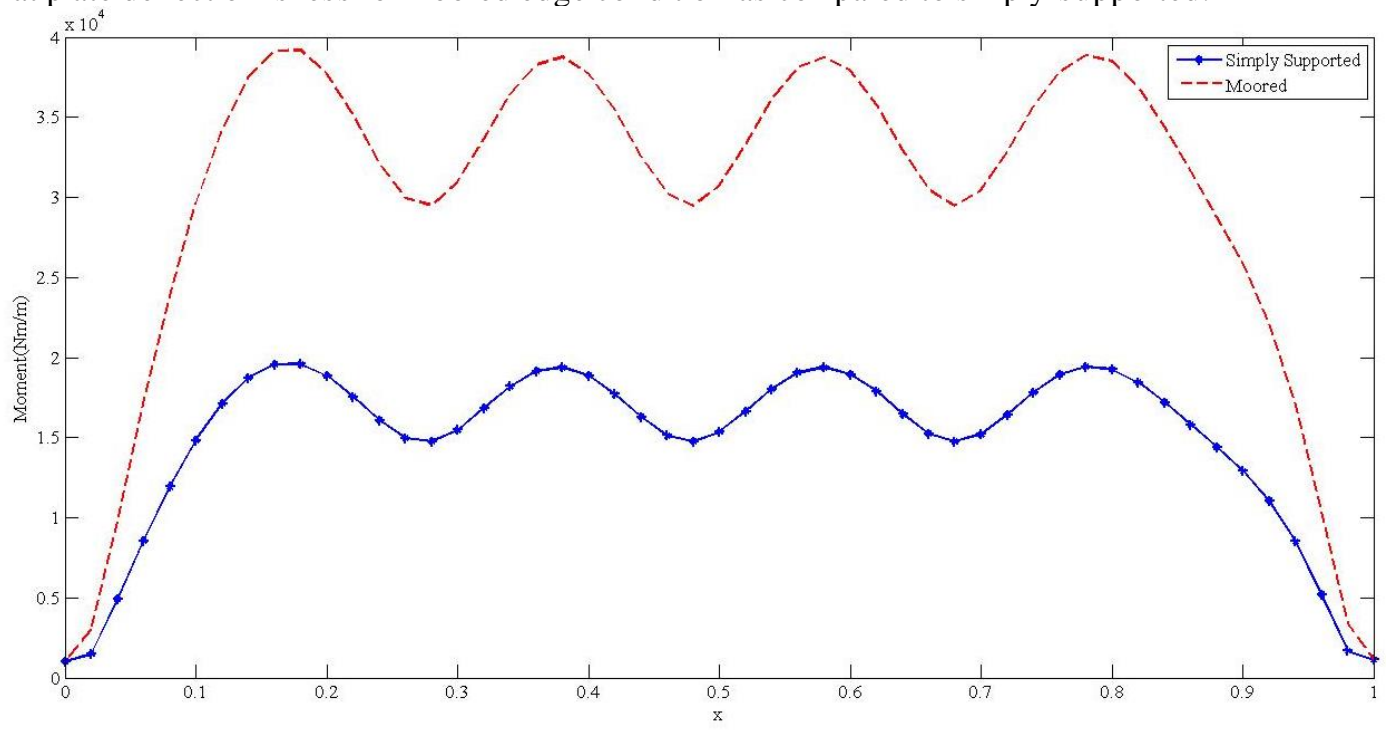

Fig. 6: Comparison of moment for rectangular plate with moored and simple support conditions $(L / \lambda=12)$

Fig. 6 shows that bending moment in the plate with simply-supported edge is having lesser value than the plate with moored edge condition. For moored condition the restraint is only the spring attached to its ends so the moment is high as compared with simple support. For both the cases, the numerical model satis fies the force boundary conditions i.e zero moments at the supports. Fig. 7 shows the comparis on of all three support conditions. It is observed that the maximum moments are $7.75 \times 10^{4} \mathrm{Nm} / \mathrm{m}, 2 \times 10^{4} \mathrm{Nm} / \mathrm{m}$ and $3.75 \times 10^{4} \mathrm{Nm} / \mathrm{m}$ for Free-Free, simple support and moored conditions, respectively. Also, the moment reduces when edges of the floating plate is restrained. 


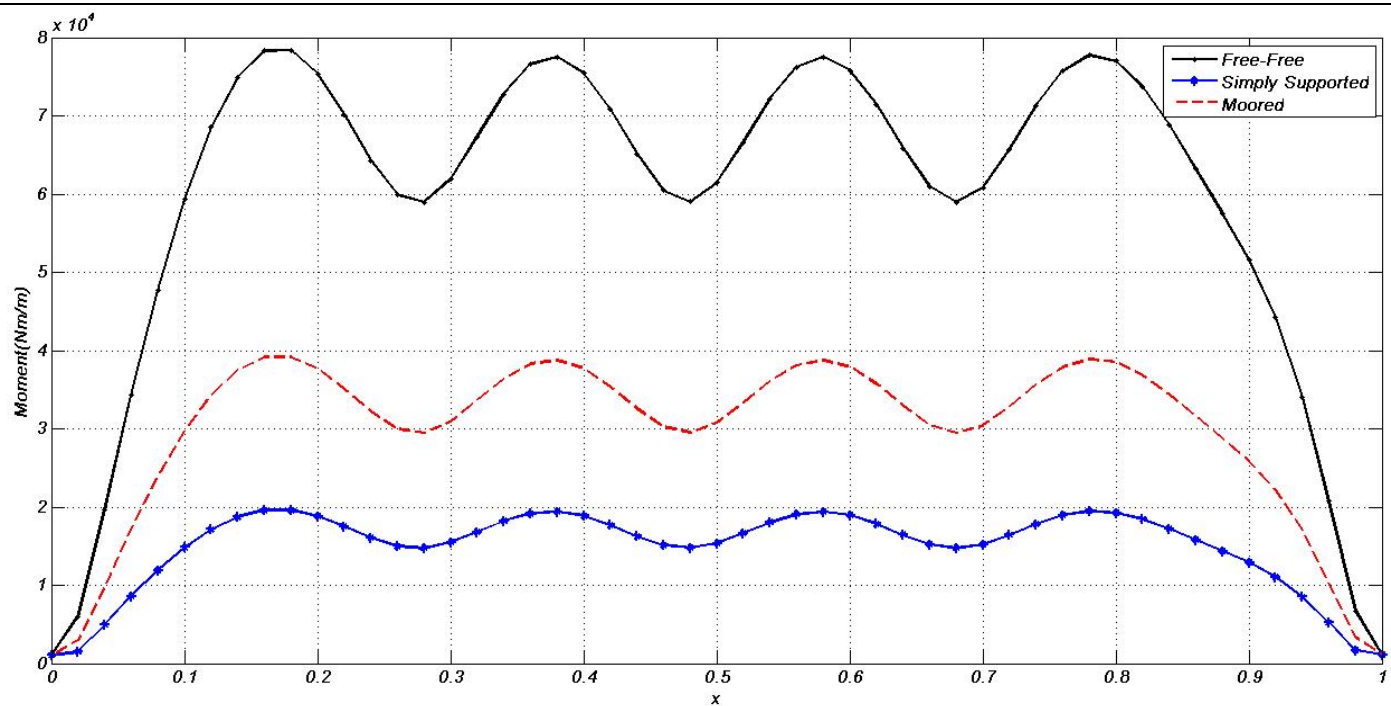

Fig. 7: Comparison of moment for rectangular plate with all the support conditions $(L / \lambda=12, d / L=0.1)$

Further, floating plate is analysed for deflection and bending moment for all the support conditions by considering plate length to wave length ratio of higher magnitude $(L / \lambda=333)$ and parameters given in Table 2.

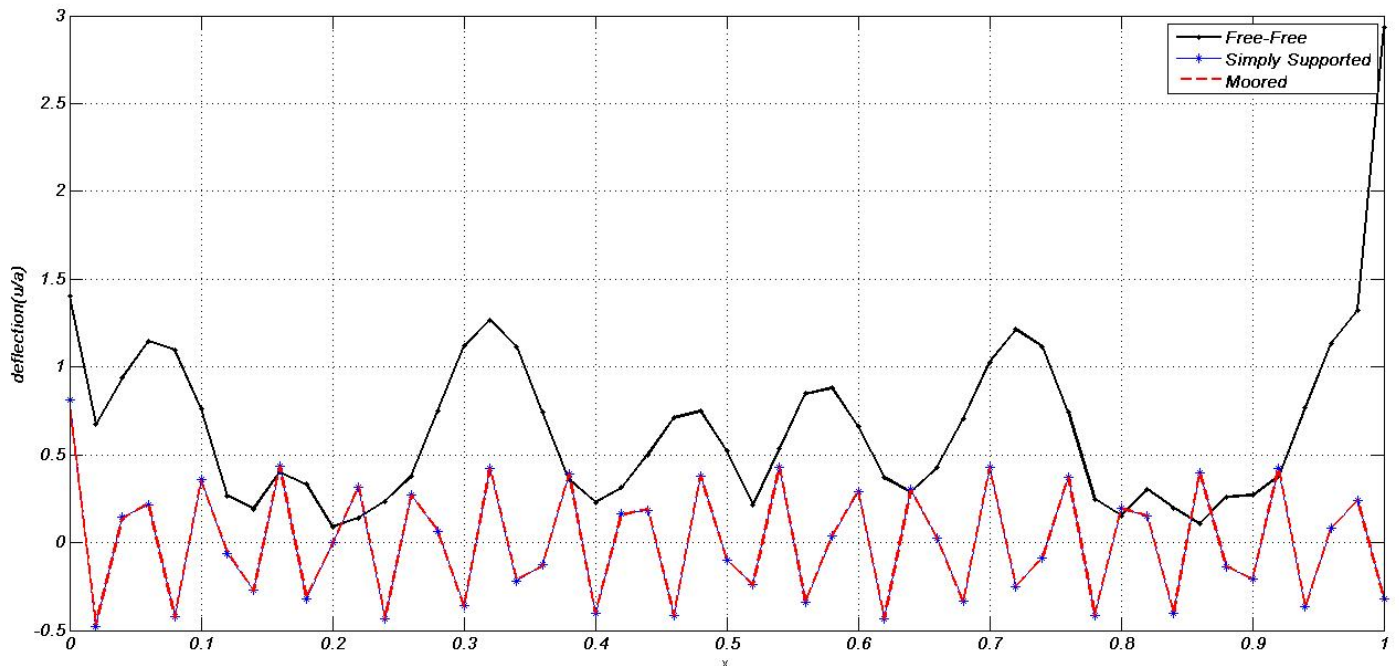

Fig. 8: Comparison of deflection for rectangular plate with all the support conditions $(L / \lambda=333, d / L=0.001)$

Table 2: Parametric Details of numerical models used to study the analysis

\begin{tabular}{|l|l|}
\hline Parameters & Magnitude \\
\hline Length, $L$ & $1000 \mathrm{~m}$ \\
\hline Breadth, $B$ & $100 \mathrm{~m}$ \\
\hline Draft, $d$ & $1 \mathrm{~m}$ \\
\hline Youngs modulus, $E$ & 5.789 \\
\hline Structural density, $\rho_{s}$ & 8.5690 \\
\hline Density of water, $\rho_{w}$ & 1025 \\
\hline Water depth, $h$ & $20 \mathrm{~m}$ \\
\hline Wavelength, $\lambda$ & $3 \mathrm{~m}$ \\
\hline
\end{tabular}

Fig. 8 and Fig. 9 depict the variation of deflection and bending moment throughout its length for an aspect ratio, $L / \lambda=333$, respectively. It is observed that the profile of the deflection is almost same with values at the edges as, 1.4 and 2.75 for free-free and 0.8 and -0.25 for both simple support and moored edge conditions, of aspect ratios, $L / \lambda=25$ and $L / \lambda=12$ (See Fig.2) for free-free condition. Further, it is observed that the deflection of moored and simple support conditions almost coincides. This gives an intuition that the restraints have less 
A. I. Shirkol, T. Nasar /Journal of Naval Architecture and Marine Engineering, 14(2017) 11 5-133 influence on magnitude of deflection for the restraints considered. Also, the deflection can be decreased either by applying greater restrained at edges i.e by adopting clamped support or by changing material properties. The maximum bending moment for free-free condition is $13.5 \times 10^{5} \mathrm{Nm} / \mathrm{m}, 7.1 \times 10^{5} \mathrm{Nm} / \mathrm{m}$ for moored condition and $2.75 \times 10^{5}$ for simple support which are higher in magnitude than that of $L / \lambda=25, L / \lambda=12$ and $L / \lambda=0.7$. Increase in bending moment of plate is due to increase in aspect ratio of floating plate. Bending moment in the plate can be minimized by increasing thickness of plate for all three support conditions. For moored condition, it can be reduced by incorporating the stiffer spring.

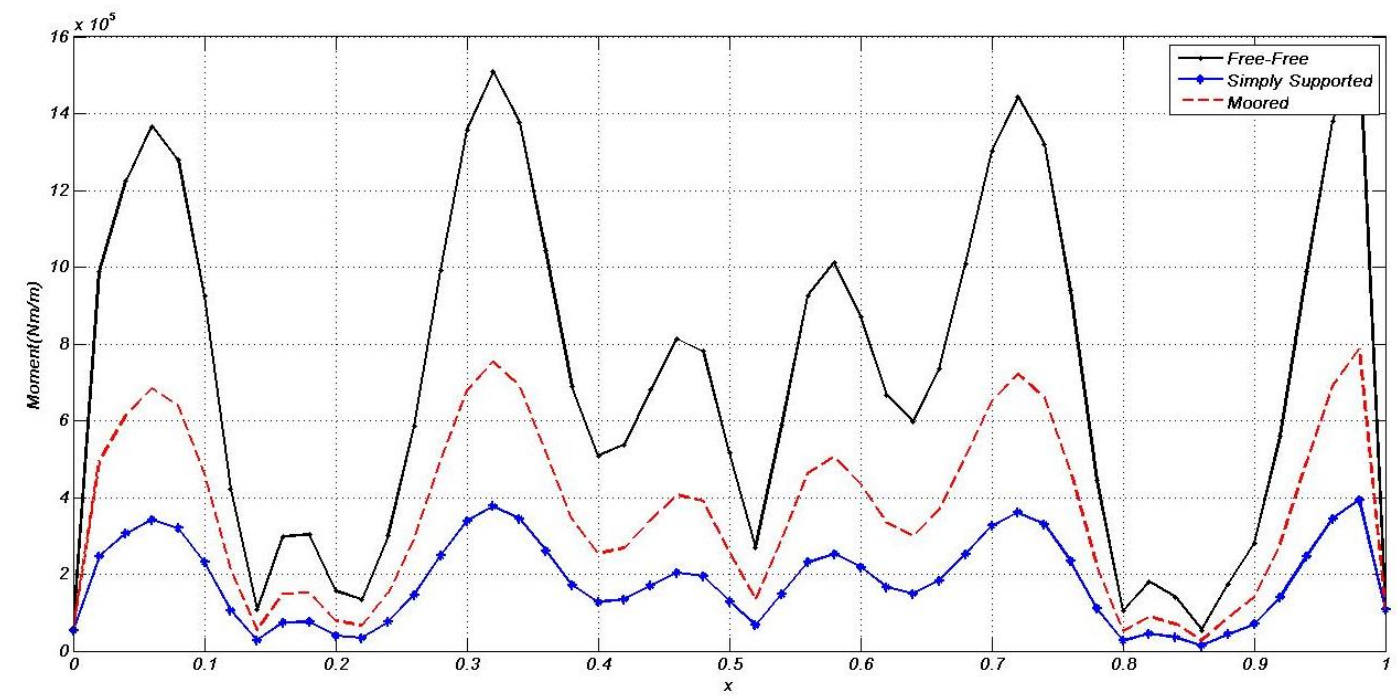

Fig. 9: Comparison of moment for rectangular plate with all the support conditions $(L / \lambda=333, d / L=0.001)$

Table 3: Parametric details of numerical models used to study the analysis

\begin{tabular}{|l|l|}
\hline Parameters & Magnitude \\
\hline Length, $L$ & $1000 \mathrm{~m}$ \\
\hline Breadth, $B$ & $100 \mathrm{~m}$ \\
\hline Draft, $d$ & $5 \mathrm{~m}$ \\
\hline Youngs modulus, $E$ & 5.789 \\
\hline Structural density, $\rho_{s}$ & 8.5690 \\
\hline Density of water, $\rho_{w}$ & 1025 \\
\hline Water depth, $h$ & $20 \mathrm{~m}$ \\
\hline Wavelength, $\lambda$ & $3 \mathrm{~m}$ \\
\hline
\end{tabular}

Fig. 10 shows comparison of deflection for three support conditions and for $L / \lambda=333, d / L=0.005$, The nondimensional displacement values at the supports are 0.27 and $0.4,0.9$ and -0.2 and -0.63 and -0.65 for free-free, simple support and moored conditions, respectively. These values are lesser in magnitude as compared with values (1.4 and 2.75 for free-free and 0.8 and -0.25 for both simple support and moored edge conditions) obtained for $L / \lambda=333, d / L=0.001$. The decrease in displacement is due to the increase in thickness of floating plate. In the case of free-free condition, it is observed that the deflection is lesser than other two edge conditions (simply support and moored) for $d / L=0.005$ as compared with the deflection obtained for $d / L=0.001$. This implies that thickness of plate plays significant role on the deflection of plate and subjected to further analysis.

Results have been discussed for Rectangular plate in the foregoing sections. In our next step, different shapes of floating platform such as Circular and Triangular platforms have been considered in order to understand sophistication of the numerical model. In the same formulation, Moment of Inertia (both mass and area) is used as key input for the different shapes and displacement of all the shapes with different type of support conditions were calculated. 
A. I. Shirkol, T. Nasar /Journal of Naval Architecture and Marine Engineering, 14(2017) 11 5-133

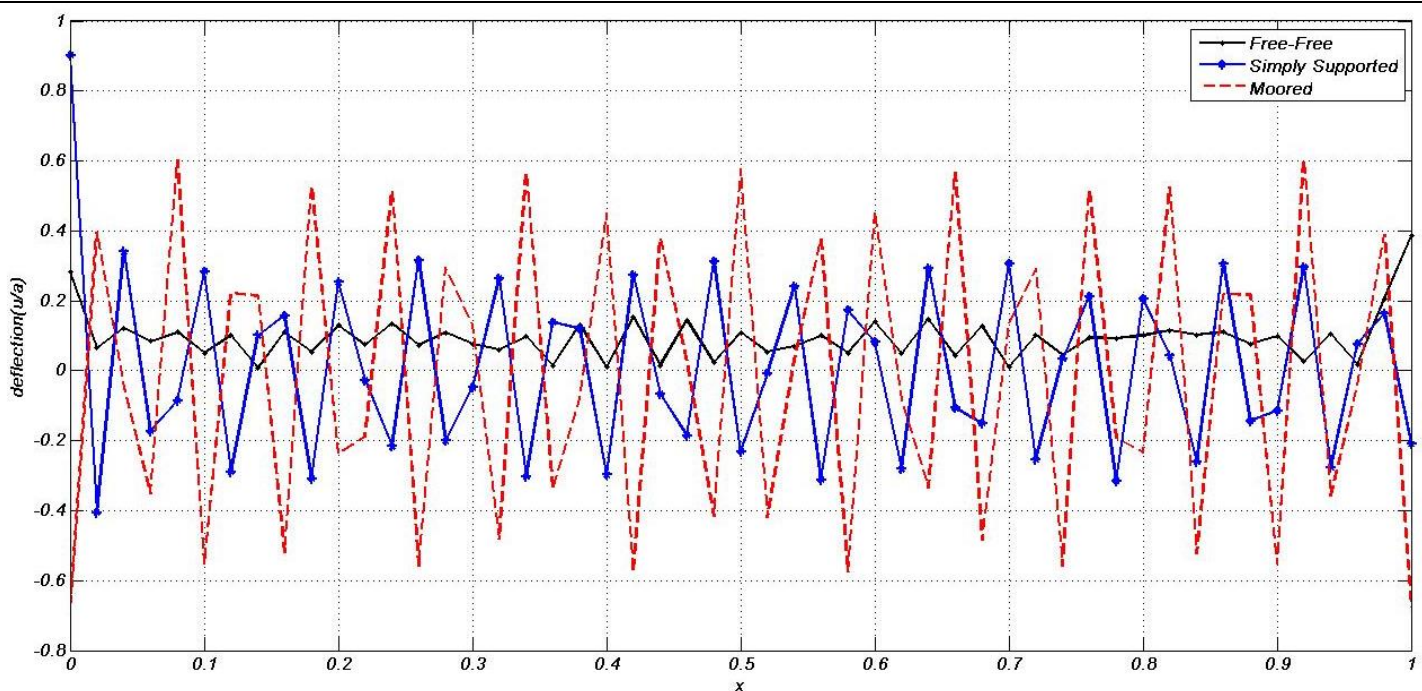

Fig.10: Comparis on of deflection for rectangular plate with all support conditions $(L / \lambda=333, d / L=0.005)$

Table 4: Parametric Details of numerical models used to study the analysis

\begin{tabular}{|l|l|}
\hline Parameters & Magnitude \\
\hline radius, $r$ & $100 \mathrm{~m}$ \\
\hline Moment of Inertia & $98.5 \times 10^{6} \mathrm{~mm}^{4}$ \\
\hline Draft, $d$ & $5 \mathrm{~m}$ \\
\hline Youngs modulus, $E$ & 5.789 \\
\hline Structural density, $\rho_{s}$ & 8.5690 \\
\hline Density of water, $\rho_{w}$ & 1025 \\
\hline Water depth, $h$ & $20 \mathrm{~m}$ \\
\hline Wavelength, $\lambda$ & $3 \mathrm{~m}$ \\
\hline
\end{tabular}

Fig. 11 shows the deflection for Circular plate with free-free edge conditions for the parameters mentioned in Table 4. At the edges, deflections are observed similar to rectan gular plate due to the free-free support condition and also it is seen that maximum non-dimensional deflection of 0.15 and 0.25 is obtained for $D / \lambda=66$ and $d / D=0.025$, where $D$ is the diameter of the plate.

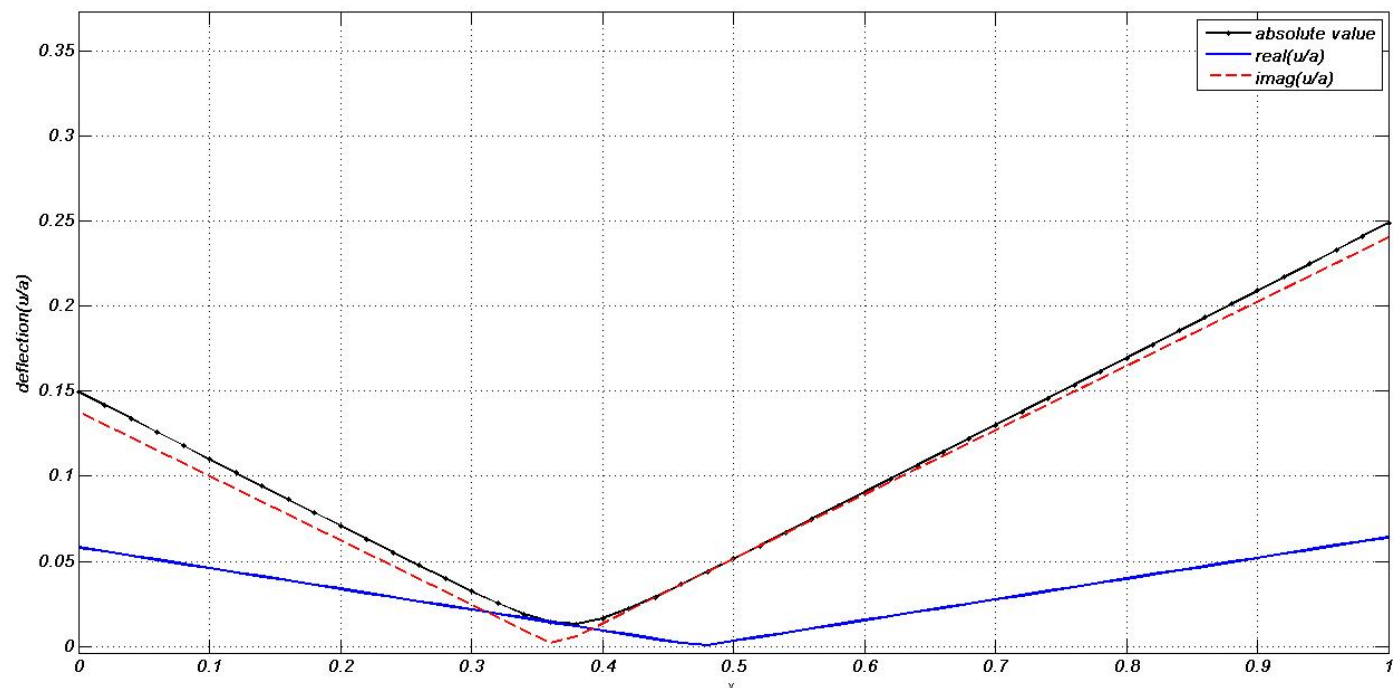

Fig.11: Convergence Test and Deflection of circular plate with free-free edge condition $(D / \lambda=66, d / D=0.025)$ 


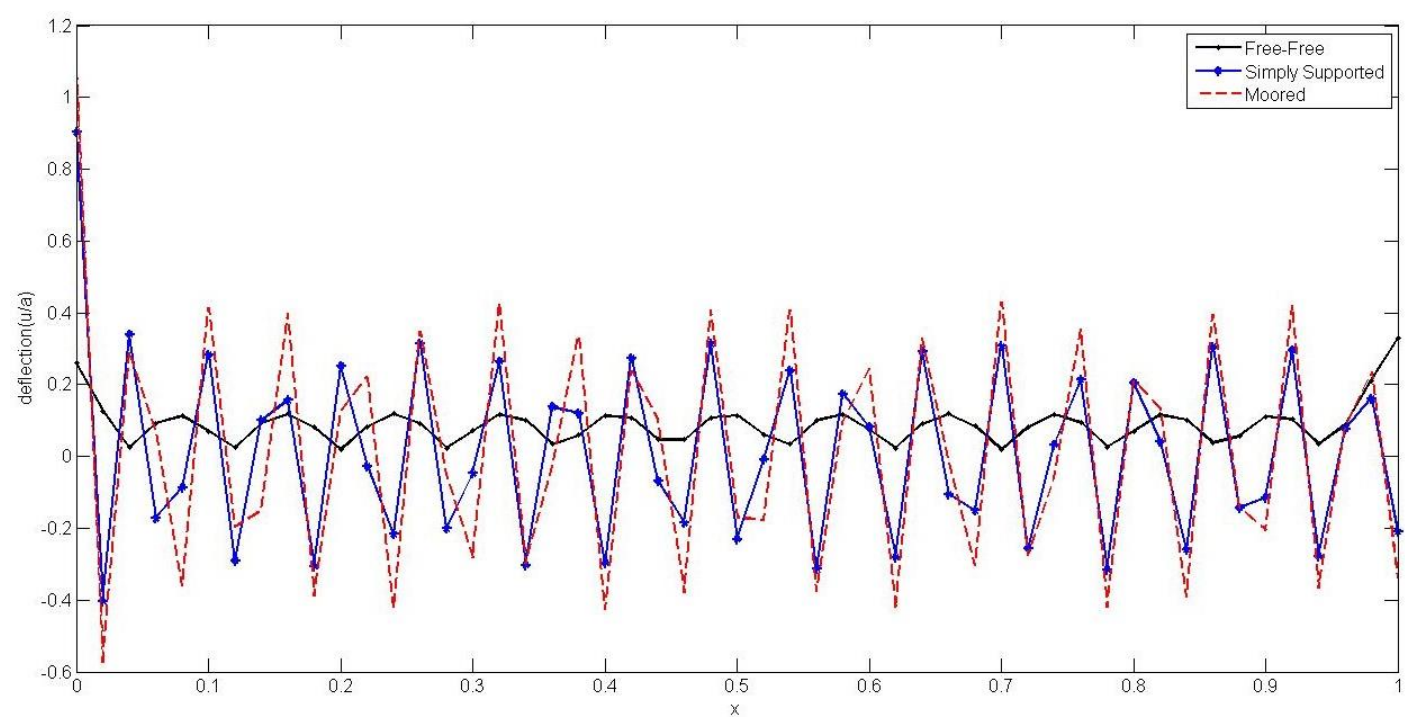

Fig. 12: Comparison of Deflection of circular plate with simple and moored edge condition $(D / \lambda=66$, $d / D=0.025$

The analysis is performed by considering three types of support conditions such as simple supported and moored edge and free-free (Fig.12). In the case of moored edge condition, the added spring stiffness, $K_{m}=$ $10 \mathrm{~N} / \mathrm{m}$ is considered for the numerical computation. The trend in variation of deflection is similar for both moored and simple supported conditions. However, for simple support, the non-dimensional deflections at edges are 0.9 and -0.2 . At moored supports, the deflections are 1.0 and -0.3 .

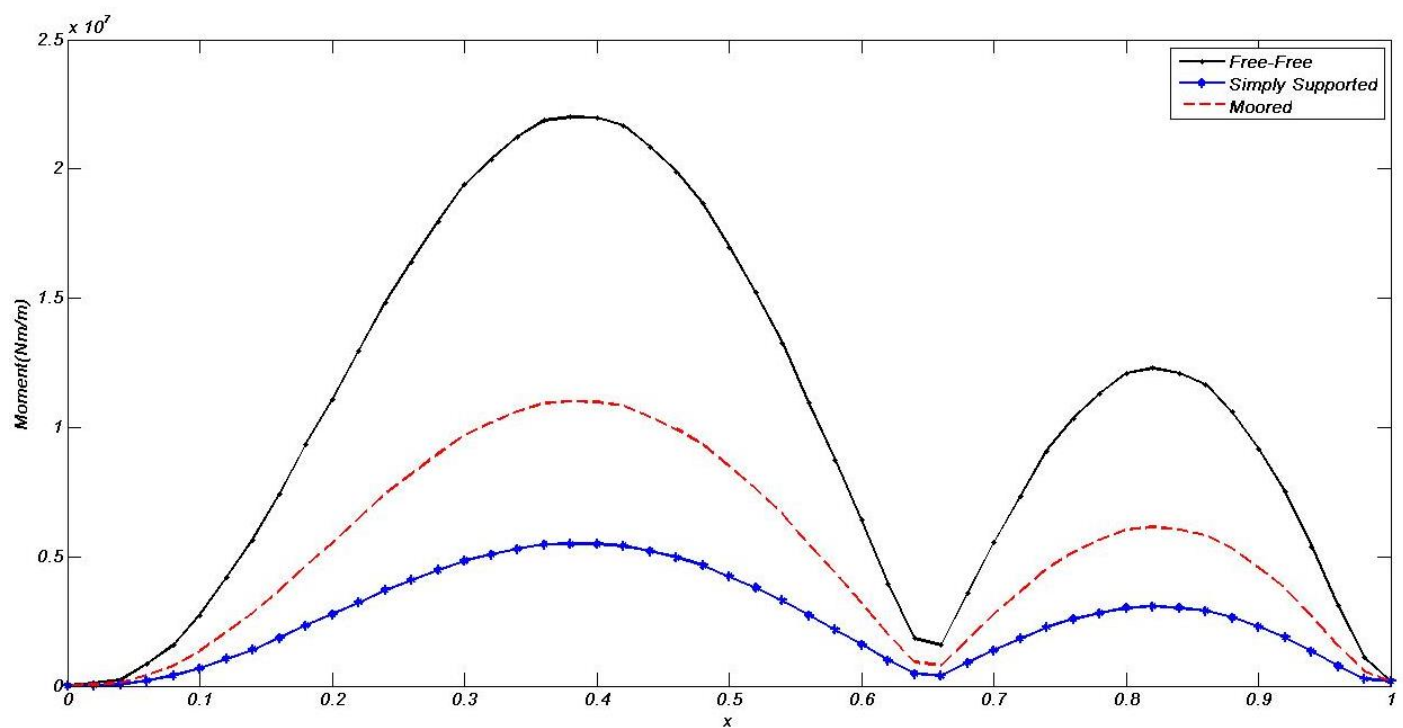

Fig. 13: Comparison of bending moment in circular plate with free-free, simple and moored edge conditions $(D / \lambda=66, d / D=0.025)$

The variation of bending moment in circular plate is shown in Fig. 13 for free-free, simple and moored support conditions. It is observed that the trend in variation is highest for free-free edge condition and its maximum value is $2.25 \times 10^{7} \mathrm{Nm} / \mathrm{mm}$. A similar trend in variation is observed for simple and moored edge conditions. The maximum bending moments are $5.50 \times 10^{6} \mathrm{Nm} / \mathrm{mm}$ and $1.150 \times 10^{7} \mathrm{Nm} / \mathrm{mm}$ for simple and moored edge conditions, respectively.

An attempt has been made for triangular shape plate as well. The regular wave has been incident on triangular floating plate with wave parameters mentioned in the Table 5. The convergence is obtained at $N \geq 50$ as it converged in rectangular plate. The convergence test and deflection for free-free condition is projected in Fig. 
A. I. Shirkol, T. Nasar /Journal of Naval Architecture and Marine Engineering, 14(2017) 11 5-133 14. The trend in variation of deflection (Fig.15) is similar for both moored and simple support conditions. Also, the deflections at edges are observed to be having either positive or negative values. The diffe rence between the deflections is less for moored and simple support conditions. Further, it is observed that the free-free condition gives the least value of deflections at the edges and in its length wise as well.

Table 5: Parametric Details of numerical models used to study the analysis

\begin{tabular}{|l|l|}
\hline Parameters & Magnitude \\
\hline Length, $L$ & $1000 \mathrm{~m}$ \\
\hline Breadth, $B$ & $10 \mathrm{~m}$ \\
\hline Draft, $d$ & $5 \mathrm{~m}$ \\
\hline Youngs modulus, $E$ & 5.789 \\
\hline Structural density, $\rho_{s}$ & 8.5690 \\
\hline Density of water, $\rho_{w}$ & 1025 \\
\hline Water depth, $h$ & $20 \mathrm{~m}$ \\
\hline Wavelength, $\lambda$ & $3 \mathrm{~m}$ \\
\hline
\end{tabular}

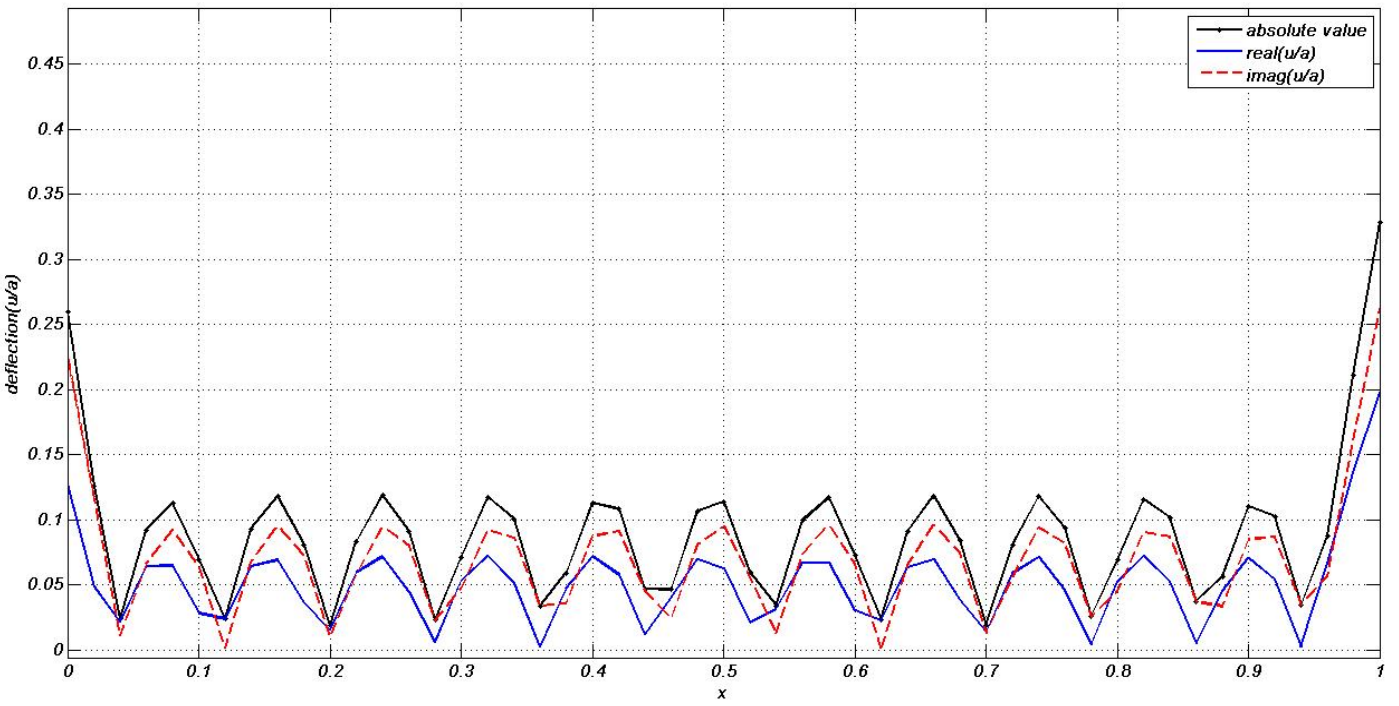

Fig. 14: Convergence test and deflection of triangular plate with free-free edge condition $(L / \lambda=333, d / L=0.005)$

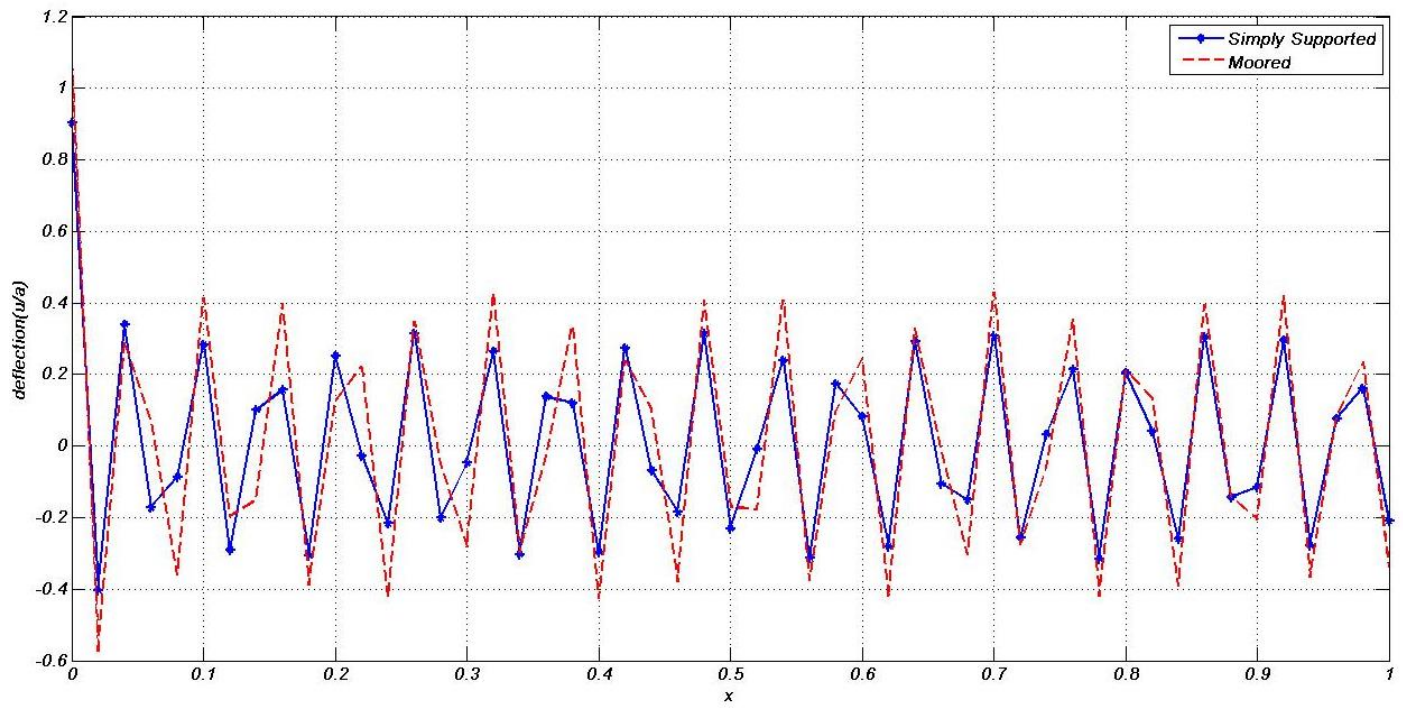

Fig. 15: Deflection of triangular plate with simple and moored edge condition $(L / \lambda=333, d / L=0.005)$ 


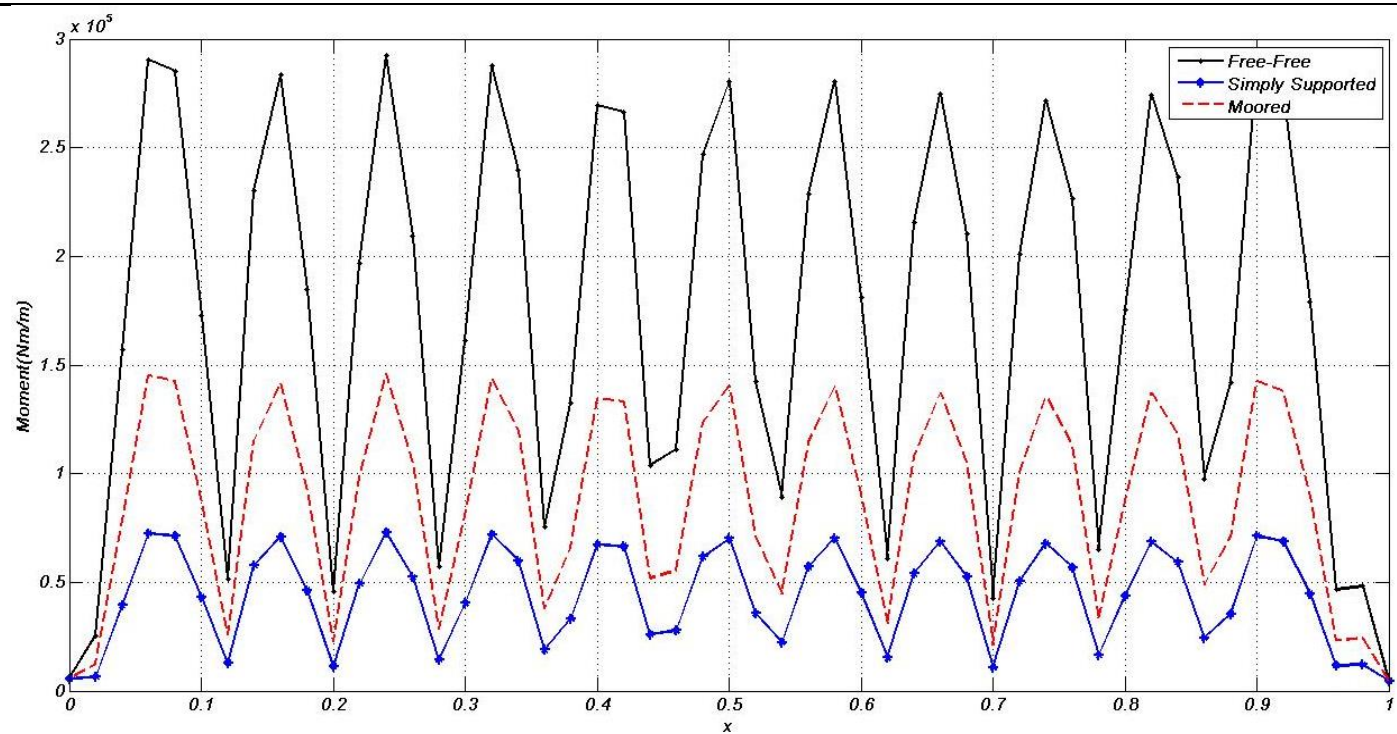

Fig. 16: Comparison of bending moment of triangular plate with free-free, simple and moored edge conditions $(L / \lambda=333, d / L=0.005)$

Fig. 16. depicts the bending moment for Triangular floating plate with different support conditions. The maximum bending moments are $2.9 \times 10^{9} \mathrm{Nm} / \mathrm{mm}, 1.4 \times 10^{9} \mathrm{Nm} / \mathrm{mm}$ and $0.75 \times 10^{9} \mathrm{Nm} / \mathrm{mm}$ for free-free, moored and simple support edge conditions, respectively.

\section{Conclusions}

In order to explore the structural behaviour of Very Large Floating Structu re (VLFS), a numerical model has been developed using Boundary Element Method (BEM) which is based on a Galerkin approximation and the same is validated both by analytical and experimental results of $\mathrm{Wu}$ et al (1995). The structure modelled as elastic thin plate by using Kirchoffs love theory. The fluid structure interaction is modelled without considering the added mass and potential damping.

In the present study, the efficacy of the developed numerical model for analysing the wave- floating plate interaction with different support conditions (free-free, simple and moored) and shapes (rectangle, circular and Triangle) is studied. It is assumed that the floating plate is considered as a strip and wave incident is parallel to the strip. The thin plate deflection characteristics and wave induced bending moments are studied in detail and as a validation of the numerical model, the force boundary conditions due to restrained effects are checked.

The convergence of plate deflection showed that minimum number of elements required for the convergence is 50. The wave structure interaction problem is solved by using fluid structure coupling equations. In the present model, diffraction and radiation terms can easily be extracted from the coupled equations. The couple d equation satisfies all the boundary conditions for any shapes and for any support conditions, with proper Centre of Gravity system and Moment of Inertia and hence the deflection and bending moment of the plate can be analysed through this model.

The following salient results/conclusions are drawn from the present study. It is observed that the individual diffraction, radiation and hydrostatic components are all much larger in magnitude than their combined effect. At the trough of the incident wave the effect of diffraction is very low due to small draft of the beam but at the crest of the incident wave the diffraction force increases tremendously. In the case of rectangular plate, three different aspect ratios $L / \lambda=12$ with $d / L=0.1, L / \lambda=333$ with $d / L=0.001$ and $L / \lambda=333$ with $d / L=0.005$ are considered in order to validate the model with the available literature. However, for the comparison between rectangle and triangular shapes and for different support conditions, $L / \lambda=333$ with $d / L=0.005$ is considered. In the case of rectangular plate, for an aspect ratio of $L / \lambda=333$ with $d / L=0.005$, the maximum deflection at the edges are 0.27 and $0.4,0.9$ and -0.2 and -0.63 and -0.65 for free-free, simple support and moored conditions, respectively. However, the deflections for triangle shape are 0.25 and $0.33,0.9$ and -0.2 and 1 and -0.3 for freefree, simple support and moored conditions, respectively. In the case of circular plate, for an aspect ratio of 
$D / \lambda=66$ with $d / D=0.025$, it is observed that the deflections at the supports are 0.15 and $0.25,0.9$ and -0.2 and 0.9 and -0.2 for free-free, simple support and moored conditions, respectively.

It is observed that the maximum bending moments for rectangular plate are $13.5 \times 10^{5} \mathrm{Nm} / \mathrm{m}, 2.75 \times 10^{5} \mathrm{Nm} / \mathrm{m}$ and $7.1 \times 10^{5} \mathrm{Nm} / \mathrm{m}$ for Free-Free, simple support and moored conditions, respectively. For triangular plate, the moments are $2.9 \times 10^{9} \mathrm{Nm} / \mathrm{mm}, 0.75 \times 10^{9} \mathrm{Nm} / \mathrm{mm}$ and $1.4 \times 10^{9} \mathrm{Nm} / \mathrm{mm}$ as in the same order of support conditions mentioned for rectangular plate. In circular plate the maximum moments are observed as $2.25 \times 10^{7} \mathrm{Nm} / \mathrm{mm}$, $5.50 \times 10^{6} \mathrm{Nm} / \mathrm{mm}$ and $1.150 \times 10^{7} \mathrm{Nm} / \mathrm{mm}$.

From the present study of limited analysis, the following qualitative statement can be made. In the case of rectangular plate with free-free edge condition and for an aspect ratio of $L / \lambda=333$ with $d / L=0.005$, the maximum deflection is at the edges of the plate but for the case of simply-supported edge the deflection is zero. In the case of moored edge condition, the deflection is less as compared to free edge condition, but, the deflection of the plate is relatively high for simply-support and moored edge conditions. It is clear that the overall response of the floating plate is extremely sensitive to its support conditions and ratio of draft to plate length. But the limiting case where the plate width is extended to approach a case equivalent to the beam model has not been attempted, because based on the very simple numerical method described here the number of terms required to provide an adequate representation of the hydrodynamic behaviour in the transverse direction would appear to be excessive. While considering three different shapes, circular plate with moored condition having stiffness, $K_{m}=10 \mathrm{~N} / \mathrm{m}$ exhibits lesser value of deflection and bending moment than triangular and rectangular plate. Also, it is concluded that either rectangular shape with simple support or circular with moored support condition is best suited as floating platform in view analysis done based on deflection and bending moment characteristics.

\section{References}

Andrianov, A.I. and Hermans, A.J. (2005): Hydroelasticity of a circular plate on water of finite or infinite depth, Journal of Fluids and Structures, Vol. 20. No. 5, pp. 719-733.

https://dx.doi.org/10.1016/j.jfluidstructs.2005.03.002

Andrianov, A.I. and Hermans, A.J. (2008): The influence of water depth on the hydroelastic response of a very large floating platform, Marine Structures, Vol. 16, No. 5, pp. 355-371. https://dx.doi.org/10.1016/S0951$\underline{8339(03) 00023-6}$

$\mathrm{Au}$, M.C. and Brebbia, C.A. (1982): Numerical prediction of wave forces using boundary element method, Applied Mathematical Modelling, Vol. 6, pp. 218-228. https://dx.doi.org/10.1016/S0307-904X(82)80028-0

Bennetts, L. G., Alberello, A., Meylan, M. H., Cavaliere, C., Babanin, A. V., and Toffoli, A. (2015): An idealised experimental model of ocean surface wave transmission by an ice floe, Ocean Modelling, Vol 96, pp. 85-92. https://dx.doi.org/10.1016/j.ocemod.2015.03.001

Bishop, R.E.D and Price, W.G. (1979): Hydroelasticity of ships, Cambride university press, Cambridge.

Brebbia, C.A. (1978): The boundary element method for engineers, Pentech Press, London

Brebbia, C.A. and Walker, S. (1980): The boundary element techniques in engineering, Newnes Butter worths, London.

Cheng, Y., Ji, C., Zhai, G., and Oleg, G. (2016): Dual inclined perforated anti-motion plates for mitigating hydroelastic response of a VLFS under wave action, Ocean Engineering, Vol 121, pp. 572-591. https://dx.doi.org/10.1016/j.oceaneng.2016.05.044

Cho, I. H., and Kim, M. H. (2013): Transmission of oblique incident waves by a submerged horizontal porous plate, Ocean Engineering, Vol 61, 56-65. https://dx.doi.org/10.1016/j.oceaneng.2012.12.044

Gao, R. P., Tay, Z. Y., Wang, C. M., and Koh, C. G. (2011): Hydroelastic response of very large floating structure with a flexible line connection, Ocean Engineering, Vol 38(17), pp. 1957-1966. https://dx.doi.org/10.1016/j.oceaneng.2011.09.021

Goldshtein, R.V. and Marchenko, A.V. (1989): The diffraction of plane gravitational waves by edge of an ice cover, Journal of Applied Mathematics and Mechanics, Vol. 53, No. 16, pp. 731-736.

https://dx.doi.org/10.1016/0021-8928(89)90078-6

Gueret, R.A.M (2002): Interaction of free surface waves with elastic and air cushion platform, Ph. D Thesis, Delft University of Technology, ISBN 90-407-2359-5.

Karmakar D., Bhattacharjee J. and Sahoo T. (2009): Wave interaction with multiple articulated floating elastic plates, Journal of Fluids and Structures, Vol. 25, No. 6, pp. 1065-1078. https://dx.doi.org/10.1016/j.jfluidstructs.2009.03.005 
Karmakar, D. and Sahoo T. (2005): Scattering of waves by articulated floating elastic plates, Marine Structures, Vol. 18, pp. 451-471. https://dx.doi.org/10.1016/j.marstruc.2006.01.002

Khabakhpash, T.I. and Korobkin, A.A. (2002): Hydroelastic behavior of compound floating plate in waves, Journal of Engineering Mathematics, Vol. 44, pp. 21-40. https://dx.doi.org/10.1023/A:1020592414338

Kim, E., Storheim, M., Amdahl, J., Løset, S., and von Bock und Polach, R. U. F. (2017): Laboratory experiments on shared-energy collisions between freshwater ice blocks and a floating steel structure, Ships and Offshore Structures, Vol 12(4), pp. 530-544. https://dx.doi.org/10.1080/17445302.2016.1183270

Kim, J. G., Cho, S. P., Kim, K. T., and Lee, P. S. (2014): Hydroelastic design contour for the preliminary design of very large floating structures, Ocean Engineering, Vol 78, pp. 112-123.

https://dx.doi.org/10.1016/j.oceaneng.2013.11.006

Kim, K. T., Lee, P. S., and Park, K. C. (2013): A direct coupling method for 3D hydroelastic analysis of floating structures, International Journal for Numerical Methods in Engineering, Vol 96(13), pp. 842-866. https://dx.doi.org/10.1002/nme.4564

Koley, S., Mondal, R., and Sahoo, T. (2017): Fredholm integral equation technique for hydroelastic analysis of a floating flexible porous plate, European Journal of Mechanics-B/Fluids .

Lee, C.H. and Newmn, J.N. (2000): An Assessment of hydroelasticity for very large hinged vessels, Journal of Fluids and Structures, Vol. 14, pp.957-970. https://dx.doi.org/10.1006/jfls.2000.0305

Lee, K. H., and Lee, P. S. (2016): Nonlinear hydrostatic analysis of flexible floating structures, Applied Ocean Research, Vol 59, pp. 165-182. https://dx.doi.org/10.1016/j.apor.2016.05.016

Liu, Y., Li, H. J., and Li, Y. C. (2012): A new analytical solution for wave scattering by a submerged horizontal porous plate with finite thickness, Ocean Engineering, Vol 42, pp. 83-92.

https://dx.doi.org/10.1016/i.oceaneng.2012.01.001

Meylan, M. H., Bennetts, L. G., and Peter, M. A. (2017): Water-wave scattering and energy dissipation by a floating porous elastic plate in three dimensions, Wave Motion, Vol70, pp. 240-250. https://dx.doi.org/10.1016/j.wavemoti.2016.06.014

Meylan, M.H. and Squire, V.A. (1996): Response of circular ice -floe to ocean waves, Journal of Geophysical Research, Vol. 101, No. 14, pp. 8869-8884. https://dx.doi.org/10.1029/95JC03706

Mirafzali, F., Tavakoli, A., and Mollazadeh, M. (2015): Hydroelastic analysis of fully nonlinear water waves with floating elastic plate via multiple knot B-splines, Applied Ocean Research, Vol51, pp. 171-180. https://dx.doi.org/10.1016/j.apor.2015.04.001

Nelli, F., Bennetts, L. G., Skene, D. M., Monty, J. P., Lee, J. H., Meylan, M. H., and Toffoli, A. (2017): Reflection and transmission of regular water waves by a thin floating plate, Wave Motion, Vol 70, pp. 209-221. https://dx.doi.org/10.1016/j.wave moti.2016.09.003

Ohkusu, M. and Namba, Y. (2004): Hydroelastic analysis of a large floating structure, Journal of Fluids and Structures, Vol. 19, pp. 543-555. https://dx.doi.org/10.1016/j.jflu idstructs.2004.02.002

Peter, M.A., Meyler, M.N and Chung, N. (2004): Wave scattering by a circular elastic plate in water of finite depth: A closed form solution, International Journal of Offshore and Polar Engineering, Vol. 14, No. 2, pp. 8185.

Riyansyah, M., Wang, C.M. and Choo, Y.S. (2010): Connection design for two-floating beam system for minimum hydroelastic response, Marine Structures, Vol. 23, pp. 67-87.

https://dx.doi.org/10.1016/j.mars truc.2010.01.001

Rizzo FJ, (1967): An integral equation to boundary value problems of classical elstostatics, Journal of Applied Mathematics, Vol. 25, pp. 83-95. https://dx.doi.org/10.1090/qam/99907

Senjanović, I., Tomić, M., and Vladimir, N. (2015): An advanced procedure for hydroelastic analysis of very large floating airport exposed to airplane load, Proc. of 7th International Conference on Hydroelasticity in Marine Technology.

Shirkol, A. I., Nasar, T., and Karmakar, D. (2016): Wave interaction with Very Large Floating Structure (VLFS) using BEM approach-Revisited, Perspectives in Science, Vol 8, pp. 533-535.

https://dx.doi.org/10.1016/j.pisc.2016.06.012

Taylor, R.E. (2007): Hydroelastic analysis of plates and some approximations, Journal of Engineering Mathematics, Vol. 58, pp. 267-278. https://dx.doi.org/10.1007/s 10665-006-9121-7

Taylor, R.E. and Ohkusu, M. (2002): Green functions for hydroelastic analysis of vibrating free-free beams and plates, Applied Ocean Research, Vol. 22, pp. 295-314. https://dx.doi.org/10.1016/S0141-1187(00)00018-3

Tkacheva, L.A. (2001a): Surface waves diffraction on a floating elastic plate, Fluid Dynamics, Vol. 36, pp. 776789. https://dx.doi.org/10.1023/A:1013077003346

Tkacheva, L.A. (2001b): Scattering of surface waves by the edge of a floating elastic plate, Journal of Applied Mechanics and Technical Physics, Vol. 42, pp. 638-646. https://dx.doi.org/10.1023/A:1019203814292 
A. I. Shirkol, T. Nasar /Journal of Naval Architecture and Marine Engineering, 14(2017) 11 5-133

Wang, C. D., and Meylan, M. H. (2002): The linear wave response of a floating thin plate on water of variable depth, Applied Ocean Research, Vol 24(3), pp. 163-174. https://dx.doi.org/10.1016/S0141-1187(02)00025-1

Wang, S., Karmakar, D. and Guedes Soares, C. (2016): Hydroelastic impact of a horizontal floating plate with forward speed, Journal of Fluids and Structure, Vol. 60, pp.97-113.

https://dx.doi.org/10.1016/j.jfluids tructs.2015.11.005

Watanabe, E., Utsumomlya, T. and Wang, C.M. (2004): Hydroelastic analysis of pontoon type VLFS: A literature survey, Engineering Structures, Vol. 28, No. 2, pp. 245-256.

https://dx.doi.org/10.1016/i.engstruct.2003.10.001

Watanabe, E., Utsunomiya, T., Wang, C.M. and Le, T.T.H. (2006): Benchmark hydroelastic response of circular VLFS under wave action, Engineering Structures, Vol. 28, pp. 423-430.

https://dx.doi.org/10.1016/j.engstruct.2005.08.014

Wu, C., Watanabe, E. and Utsunomiya, T. (1995): An eigenfunction expansion matching method for analyzing the wave-induced responses of an elastic floating plate, Applied Ocean Research, Vol. 17, pp. 301-310. https://dx.doi.org/10.1016/0141-1187(95)00023-2

Yoon, J. S., and Lee, P. S. (2017): Towards hydro-elastoplastic analysis of floating plate structures, Journal of Fluids and Structures, Vol 71, pp. 164-182. https://doi.org/10.1016/j.jfluidstructs.2017.03.008

Zheng, S., and Zhang, Y. (2016): Wave diffraction and radiation by multiple rectangular floaters, Journal of Hydraulic Research, Vol 54(1), pp. 102-115. https://dx.doi.org/10.1080/00221686.2015.1090492

Zilman, G. and Miloh, T. (2000): Hydroelastic buoyant circular plate in shallow water: A closed form solution, Applied Ocean Research, Vol. 22, pp. 191-198. https://dx.doi.org/10.1016/S0141-1187(00)00011-0 